\title{
Monitoring and tracking the trans-Pacific transport of aerosols using multi-satellite aerosol optical depth composites
}

\author{
Aaron R. Naeger ${ }^{1}$, Pawan Gupta ${ }^{2,3}$, Bradley T. Zavodsky ${ }^{4}$, and Kevin M. McGrath \\ ${ }^{1}$ University of Alabama in Huntsville, Earth System Science Center, Huntsville, AL, USA \\ ${ }^{2}$ NASA Goddard Space Flight Center, Greenbelt, MD, USA \\ ${ }^{3}$ University Space Research Association, Columbia, MD, USA \\ ${ }^{4}$ NASA Marshall Space Flight Center, Huntsville, AL, USA \\ ${ }^{5}$ Jacobs Engineering Inc., ESSSA Group, Huntsville, AL, USA \\ Correspondence to: Aaron R. Naeger (naeger@nsstc.uah.edu)
}

Received: 20 July 2015 - Published in Atmos. Meas. Tech. Discuss.: 7 October 2015

Revised: 20 April 2016 - Accepted: 3 May 2016 - Published: 3 June 2016

\begin{abstract}
The primary goal of this study was to generate a near-real time (NRT) aerosol optical depth (AOD) product capable of providing a comprehensive understanding of the aerosol spatial distribution over the Pacific Ocean, in order to better monitor and track the trans-Pacific transport of aerosols. Therefore, we developed a NRT product that takes advantage of observations from both low-earth orbiting and geostationary satellites. In particular, we utilize AOD products from the Moderate Resolution Imaging Spectroradiometer (MODIS) and Suomi National Polar-orbiting Partnership (NPP) Visible Infrared Imaging Radiometer Suite (VIIRS) satellites. Then, we combine these AOD products with our own retrieval algorithms developed for the NOAA Geostationary Operational Environmental Satellite (GOES-15) and Japan Meteorological Agency (JMA) Multi-functional Transport Satellite (MTSAT-2) to generate a NRT daily AOD composite product. We present examples of the daily AOD composite product for a case study of trans-Pacific transport of Asian pollution and dust aerosols in mid-March 2014. Overall, the new product successfully tracks this aerosol plume during its trans-Pacific transport to the west coast of North America as the frequent geostationary observations lead to a greater coverage of cloud-free AOD retrievals equatorward of about $35^{\circ} \mathrm{N}$, while the polar-orbiting satellites provide a greater coverage of AOD poleward of $35^{\circ} \mathrm{N}$. However, we note several areas across the domain of interest from Asia to North America where the GOES-15 and MTSAT2 retrieval algorithms can introduce significant uncertainties into the new product.
\end{abstract}

\section{Introduction}

Although stricter emission control standards in the United States have led to a reduction in the domestic emissions of particulates since the 1980s, degraded air quality conditions over the western United States have occurred due to foreign dust and pollution aerosols (Yu et al., 2012). For instance, the expanding cities and rapid industrialization of East Asia are major source regions of pollution emissions while biomass burning across Southeast Asia releases smoke into the atmosphere (e.g., Streets et al., 2003). In addition, frequent dust storms originate from the Taklamakan and Gobi deserts in the late winter and early spring, with a daily average dust emission of 1.58 million tons in April (Zhao et al., 2006). These smoke and dust aerosols combine with the other pollutants in a trans-Pacific transport that occurs frequently during late winter and early spring when the East Asian winter monsoon is near its peak strength (Gong et al., 2006). This East Asian winter monsoon brings cold, dry air outbreaks, leading to strong surface winds that can efficiently pick up dust from the deserts. Once lofted in the atmosphere, the dust, smoke, and pollution aerosols are quickly transported to the western Pacific by a persistent offshore wind flow from the Asian continent (Talbot et al., 1997). Then, the aerosols are carried by strong mid- to upper-level westerly winds across the Pacific to the western United States where they can be transported from the free troposphere towards the ground. These transported aerosols can reduce the air quality across the United States which can increase the risk of 
lung cancer and cardiopulmonary mortalities (e.g., Pope et al., 2002). Consequently, limiting domestic emissions in the United States alone does not assure that the aerosol effects on human health will be reduced, as the total mass of aerosols entering the United States from overseas is similar to that emitted domestically (Yu et al., 2012). Not only can aerosols degrade the air quality, but they can also have direct and indirect radiative effects in the atmosphere through interaction with solar radiation and clouds which can have significant impacts on the climate and weather (e.g., Khain et al., 2005; Ault et al., 2011; Naeger et al., 2013a). Therefore, it is important that we continuously monitor aerosols at a global scale, and determine their concentration and spatial variability, especially during the late winter and early spring period when the trans-Pacific transport of Asian aerosols occurs rather frequently.

A major issue when attempting to monitor aerosols across the Pacific is the large amount of cloud cover that often resides over this region. Mace et al. (2009) used merged data from the Cloud-Aerosol Lidar and Infrared Pathfinder Satellite Observations (CALIPSO) and CloudSat satellite to show that cloud cover exceeded $90 \%$ throughout the North Pacific between July 2006 and June 2007. Aerosol optical depth (AOD) retrieval algorithms generally disregard AOD in cloudy regions via cloud screening techniques due to the difficulty in separating the visible reflectance of aerosols and clouds that lead to biases in the retrievals. However, even the more robust cloud screening techniques, such as those used for the Moderate Resolution Imaging Spectroradiometer (MODIS) (Frey et al., 2008), are unable to detect all clouds due to the highly diverse surface and atmospheric conditions that exist across the Earth (Ackerman et al., 2008). Further complicating matters include the adjacency effect where reflected light from clouds can brighten nearby cloud-free pixels (e.g., Wen et al., 2001). Zhang et al. (2005) found that cloud contamination and adjacency effects lead to an overestimation of $10-20 \%$ in the monthly averaged MODIS AOD over oceans. The MODIS Collection 6.0 AOD product has been refined to reduce the cloud contamination issues in Collection 5.1 (Levy et al., 2013). Nonetheless, cloud cover continues to hinder our ability to monitor the trans-Pacific transport of aerosols when using observations from passive (low-earth orbiting, LEO) satellites alone. There has been recent progress in retrieving AOD for absorbing aerosols above clouds from MODIS (Jethva et al., 2013; Meyer et al., 2015) and the Ozone Monitoring Instrument (OMI) (Torres et al., 2012), which could prove very beneficial for tracking the trans-Pacific transport of aerosols. These retrieval techniques take advantage of the highly reflective nature of clouds along with the absorption characteristics of aerosols in the near-UV to visible wavelengths to retrieve AOD when aerosols are lofted above clouds. However, these retrieval techniques rely on a larger number of assumptions than cloud-free aerosol retrievals, which often leads to significant uncertainties of greater than $50 \%$ (Jethva et al., 2013; Torres et al., 2012). The CALIPSO satellite carries the active Cloud-Aerosol Lidar and Orthogonal Polarization (CALIOP) instrument that is more equipped for detecting aerosol plumes above cloud layers (Winker et al., 2010). However, the CALIOP is of limited value for monitoring the spatial variability of aerosols due to its extremely narrow field of view; therefore, it will only be used to help validate our product.

US air quality agencies (e.g., Environmental Protection Agency, EPA) rely on near-real time (NRT) aerosol products to help provide better forecasts while incorporating the NRT data into their analysis (Al-Saadi et al., 2005). By providing the public with more accurate air quality forecasts, individuals can appropriately adjust their outdoor activities to avoid exposure to poor air quality conditions which can have harmful health impacts. Furthermore, the aerosol indirect effects have recently been incorporated into the Rapid Refresh (RAP) operational model forecast system at the NOAA National Centers for Environmental Prediction (Benjamin et al., 2016). Currently, aerosol fields initialized in the RAP model are based on climatology. Thus, NRT aerosol products can be used to help initialize these operational forecast models with a realistic depiction of the aerosol conditions.

In this study, we merge observations from LEO and geostationary (GEO) satellites in order to develop a NRT 6hourly and daily AOD composite product centered over the Pacific Ocean. The new product will demonstrate the benefits of merging LEO and GEO satellite observations for tracking aerosol plumes in the atmosphere and has the potential to be useful for data assimilation and aerosol forecasting. For instance, the National Aeronautics and Space Administration (NASA) Goddard Earth Observing System version 5 (GEOS-5) model (Rienecker et al., 2008; Molod et al., 2012) only assimilates aerosol observations from MODIS, but having more frequent satellite observations such as from this study may help model simulation and forecasting of aerosol fields. In the following sections, we discuss the data products used in this study (Sect. 2), present the methodology for generating the NRT AOD composite product (Sect. 3), show results from a case study of trans-Pacific transport of Asian aerosols (Sect. 4), discuss uncertainties (Sect. 5) and validation (Sect. 6), and conclude with a summary and discussion (Sect. 6).

\section{Data}

Table 1 provides a detailed summary of the different satellites and aerosol retrievals used in generating our NRT 6-hourly and daily AOD composite product.

\subsection{MODIS}

We utilize the MODIS instrument on board the LEO Aqua and Terra satellites, which has 36 spectral bands with center wavelengths between 0.41 and $14.5 \mu \mathrm{m}$ and spatial resolu- 
Table 1. Summary of satellites instruments used in producing the NRT AOD product

\begin{tabular}{|c|c|c|c|c|c|c|c|c|c|}
\hline Satellite & $\begin{array}{l}\text { Instrument/ } \\
\text { orbit }\end{array}$ & $\begin{array}{l}\text { Spectral } \\
\text { bands }\end{array}$ & $\begin{array}{l}\text { Repeat } \\
\text { cover- } \\
\text { age }\end{array}$ & $\begin{array}{l}\text { Swath } \\
\text { width } \\
(\mathrm{km})\end{array}$ & $\begin{array}{l}\text { Equator } \\
\text { crossing time } \\
\text { (UTC) }\end{array}$ & $\begin{array}{l}\text { Bands for } \\
550 \mathrm{~nm} \text { AOD } \\
\text { retrieval }\end{array}$ & $\begin{array}{l}\text { Spatial } \\
\text { resolution } \\
\text { of AOD } \\
\text { (nadir) }\end{array}$ & $\begin{array}{l}\text { Latency } \\
(\min )\end{array}$ & $\begin{array}{l}\text { AOD } \\
\text { uncertainty }\end{array}$ \\
\hline Aqua/Terra & MODIS/LEO & 36 & $\begin{array}{l}1 \text { to } 2 \\
\text { days }\end{array}$ & 2330 & $\begin{array}{l}\text { Aqua - 10:30 } \\
\text { Terra - 13:30 }\end{array}$ & $\begin{array}{l}\text { 1: 620-670 } \\
3: 459-479\end{array}$ & $\begin{array}{l}10 \times 10 \mathrm{~km} \\
\left(100 \mathrm{~km}^{2}\right)\end{array}$ & $\sim 90$ & $\begin{array}{l} \pm 0.03 \pm 0.05 \times \\
\text { AOD over ocean }\end{array}$ \\
\hline S-NPP & VIIRS/LEO & 22 & daily & 3000 & $13: 30$ & $\begin{array}{l}\text { M5: 662-682 } \\
\text { M3: } 478-488\end{array}$ & $\begin{array}{l}6 \times 6 \mathrm{~km} \\
\left(36 \mathrm{~km}^{2}\right)\end{array}$ & $\sim 420$ & $\begin{array}{l}\text { Similar to } \\
\text { MODIS }\end{array}$ \\
\hline GOES-15 & Imager/GEO & 5 & $30 \mathrm{~min}$ & $\mathrm{n} / \mathrm{a}$ & $\mathrm{n} / \mathrm{a}$ & 1: 533-709 & $\begin{array}{l}4 \times 4 \mathrm{~km} \\
\left(16 \mathrm{~km}^{2}\right)\end{array}$ & $<30$ & $\begin{array}{l}18-34 \% \text {; lower } \\
\text { over water }\end{array}$ \\
\hline MTSAT-2 & Imager/GEO & 5 & $30 \mathrm{~min}$ & $\mathrm{n} / \mathrm{a}$ & $\mathrm{n} / \mathrm{a}$ & 1: 540-816 & $\begin{array}{l}5 \times 5 \mathrm{~km} \\
\left(25 \mathrm{~km}^{2}\right)\end{array}$ & $<30$ & $\begin{array}{l}\text { Similar to } \\
\text { GOES-15 }\end{array}$ \\
\hline
\end{tabular}

tions of 250,500 , and $1000 \mathrm{~m}$. In general, the MODIS team retrieves AOD by comparing the reflectances from the solar bands to a look-up table of computed reflectances based on sun/satellite geometry, surface reflectance, and aerosol type (Remer et al., 2005). AOD products have been under development by the MODIS team with the most recent release of the Collection 6 Level 2 AOD product (Remer et al., 2013). In this study, we use the Collection 5.1 Level 2 AOD product, since a NRT version for Collection 6 was not released until early 2016. The Collection 5.1 release of MODIS dark target algorithm provides a $10 \mathrm{~km}$ AOD product with uncertainties over ocean and non-bright surfaces of $\pm 0.03 \pm 0.05 \times$ AOD and $\pm 0.05 \pm 0.15 \times$ AOD, respectively (Remer et al., 2005; Levy et al., 2010). MODIS AOD is usually retrieved with rather low uncertainties due primarily to the availability of numerous spectral bands. For example, the MODIS team uses seven reflective solar bands to help distinguish between aerosol types in the atmosphere, which has led to the development of a complex aerosol retrieval that uses a total of 14 different aerosol models, nine over ocean and five over land (Levy et al., 2007b). The ocean aerosol models use optical properties representative of four types of water-soluble particles, three types of wet sea salt particles, and two types of dust-like particles. Although MODIS retrieval over land only uses five aerosol models (continental, generic, non-absorbing urban-industrial, absorbing smoke, and spheroid dust), these models separate between soluble, dust, and soot-mode particles for the continental aerosol model, and accumulationand coarse-mode particles for the other four models. A noteworthy strength of the MODIS AOD retrieval algorithm is the use of the spheroid dust model (Dubovik et al., 2006), which can lead to significant improvement in characterizing the scattering of dust aerosols compared to spherical models and, consequently, reduce uncertainties in AOD (Dubovik et al., 2002; Levy et al., 2007b).

The 36 spectral bands of MODIS are also utilized to develop a robust cloud mask that prevents cloud contamination from impacting the AOD retrievals. For instance, thin cirrus clouds are difficult to detect and can cause biases in AOD when located above aerosols (Huang et al., 2011); however, the $1.38 \mu \mathrm{m}$ band on board MODIS helps mask these clouds and reduce uncertainties in AOD (Ackerman et al., 2006). MODIS also carries the $0.47,0.66$, and $2.12 \mu \mathrm{m}$ bands that help reduce AOD uncertainties by improving the estimation of surface reflectivity over dark land surfaces, such as vegetation and soils (Levy et al., 2007a). Note that the NRT version of the Collection 5.1 AOD product is distributed with an average latency of approximately 90 min via NASA's Land and Atmosphere Near real-time Capability for Earth observing system (LANCE) data system.

\subsection{VIIRS}

In addition to MODIS, our NRT product incorporates AOD retrievals from the Visible Infrared Imaging Radiometer Suite (VIIRS) on board the Suomi National Polar-orbiting Partnership (NPP) satellite (Jackson et al., 2013). The VIIRS instrument with its 22 spectral bands was designed to continue the decade-long success of retrieving AOD from MODIS; therefore, the VIIRS AOD retrieval algorithm has similar strengths to MODIS. For instance, the VIIRS aerosol retrieval uses the same nine ocean aerosol models as discussed for MODIS. The only minor difference between these ocean aerosol models is the very minimal difference in band wavelengths. Although both VIIRS and MODIS use five different aerosol models over land, they use different values of mean radius, standard deviation of volume distribution, and refractive indices to represent each model. Additionally, the dust aerosol models over land for these LEO retrievals differ in that the VIIRS dust model is based on Mie-scattering calculations that assume spherical particles while MODIS accounts for non-spherical particles. As a result, we expect VIIRS AOD to encounter higher uncertainties than MODIS when retrieving AOD for dust plumes over land. In addition, there are some significant differences between the VIIRS and MODIS cloud masks and internal screening tests (Jackson et al., 2013). Nevertheless, Liu et al. (2014) conducted an extensive validation of VIIRS AOD against the Maritime Aerosol Network (MAN) where they found that $71 \%$ of VI- 
IRS retrievals were within the expected uncertainty range of MODIS retrievals over ocean.

Although VIIRS follows the same orbit track as MODIS Aqua, it is capable of providing additional information on the spatial distribution of AOD due to a wider swath width and higher spatial resolution at swath edge than MODIS (Hillger et al., 2013). VIIRS has a swath width of 3000 vs. $2330 \mathrm{~km}$ for MODIS and a spatial resolution at swath edge of approximately $1.5 \mathrm{vs} .5 \mathrm{~km}$ for MODIS. We process AOD data from the VIIRS aerosol Environmental Data Record via the NOAA Comprehensive Large Array-data Stewardship System (CLASS) subscription service. However, the VIIRS AOD product via NOAA CLASS has approximately a $7 \mathrm{~h}$ latency (i.e., time between the satellite observation and availability of the data product) compared to the 90 min latency of MODIS AOD via NASA LANCE data system. Consequently, VIIRS retrievals are only incorporated into our daily $24 \mathrm{~h}$ AOD composite product and not into our 6-hourly product.

\subsection{GOES-15 and MTSAT-2}

Even though the advanced MODIS and VIIRS instruments provide high-quality AOD retrievals, they fly on board LEO satellites that observe the same location only once per daytime period. Thus, cloud cover can lead to large gaps in the coverage of AOD when only analyzing data from instruments on board LEO satellites, especially over the generally cloudy Pacific Ocean. To mitigate this issue and more effectively track the trans-Pacific transport of aerosols, we incorporate the high temporal resolution measurements from the NOAA Geostationary Operational Environmental Satellite (GOES-15) and Japan Meteorological Agency (JMA) Multifunctional Transport Satellite (MTSAT-2) geostationary platforms into the NRT AOD composite product. This study uses the northern hemispheric scan modes with a 30 min temporal resolution for both GOES-15 and MTSAT-2. The high temporal resolution of these GEO sensors can lead to a higher frequency of cloud-free observations than that provided by the LEO sensors, which can help increase the spatial coverage of AOD.

The major disadvantage of these imagers on board the GOES-15 and MTSAT-2 is that they only have five spectral bands, consisting of one visible and four infrared bands (Table 2), compared to the 22 and 36 bands of MODIS and VIIRS. Consequently, these GEO sensors are very limited in their capability to distinguish between various aerosol types in the atmosphere; therefore, we are unable to replicate the complex aerosol retrievals of MODIS and VIIRS. Instead, we develop simplified aerosol retrievals based on only two aerosol models (continental and desert) as discussed in Sect. 3.3. Similar to the VIIRS retrieval, the desert aerosol model used in these GEO retrievals assumes spherical particles. The surface reflectance retrievals (Sect. 3.2) and cloud masks (Sect. 3.4) developed for these GEO sensors are also
Table 2. Center wavelength and spatial resolution of spectral bands on board GOES-15 and MTSAT-2. MTSAT-2 is denoted in parentheses. The GOES-15 imager carries bands $1-4$ and 6 while the MTSAT-2 imager carries bands 1-5.

\begin{tabular}{lcc}
\hline & \multicolumn{2}{c}{ GOES-15 and (MTSAT-2) } \\
\cline { 2 - 3 } $\begin{array}{l}\text { Imager } \\
\text { band }\end{array}$ & $\begin{array}{c}\text { Center } \\
\text { wavelength }(\mu \mathrm{m})\end{array}$ & $\begin{array}{c}\text { Spatial } \\
\text { resolution }(\mathrm{km})\end{array}$ \\
\hline 1 & $0.63(0.675)$ & $1(1.25)$ \\
2 & $3.9(3.75)$ & $4(5)$ \\
3 & $6.48(6.75)$ & $4(5)$ \\
4 & $10.7(10.8)$ & $4(5)$ \\
5 & NA (12.0) & NA $(5)$ \\
6 & $13.3(\mathrm{NA})$ & $4(\mathrm{NA})$ \\
\hline
\end{tabular}

less robust than the LEO sensors due to the lower availability of spectral bands. As a result, AOD retrievals from these GEO sensors will typically have higher uncertainties than those from LEO sensors as shown by the validation study of Paciorek et al. (2008) where the GOES AOD uncertainty range over dark land surfaces was $18-34 \%$ with lower values expected over water. Similar uncertainties were associated with a MTSAT AOD retrieval algorithm when validated against ground-based instrumentation at the AErosol RObotic NETwork (AERONET) stations (Kim et al., 2008). Note that easily accessible archives containing AOD data are not available for the MTSAT-2 satellite; therefore, we develop our own retrieval algorithms for the GEO sensors in order to ensure a consistency between their algorithms. Nevertheless, the GOES AOD retrieval algorithm developed for this study has similarities to the GOES Aerosol/Smoke Product (GASP) discussed in Prados et al. (2007). The latency of our GOES and MTSAT AOD retrievals is typically less than $30 \mathrm{~min}$.

\subsection{AERONET}

In this study, we use ground-based instrumentation at AERONET stations to assist with developing accurate AOD retrieval algorithms for the GOES and MTSAT satellites. AERONET stations are located throughout the globe, but we focus on 10 of those set across eastern Asia, since aerosols usually propagate over this region prior to their trans-Pacific transport. The sun-sky radiometer instruments at the AERONET stations provide very accurate measurements of aerosol optical properties from the ultraviolet to the near-infrared (Holben et al., 1998). We utilize AOD and single scattering albedo (SSA) data at 500 and $675 \mathrm{~nm}$, then calculate the Ångström exponent by logarithmic interpolation between these wavelengths to derive AOD at $550 \mathrm{~nm}$. Reported uncertainties for the Level 2.0 cloud-screened and quality-assured AOD and SSA retrievals are approximately \pm 0.02 and \pm 0.07 , respectively (Schmid et al., 1999; Dubovik et al., 2000). The interpolation method to derive AOD at 


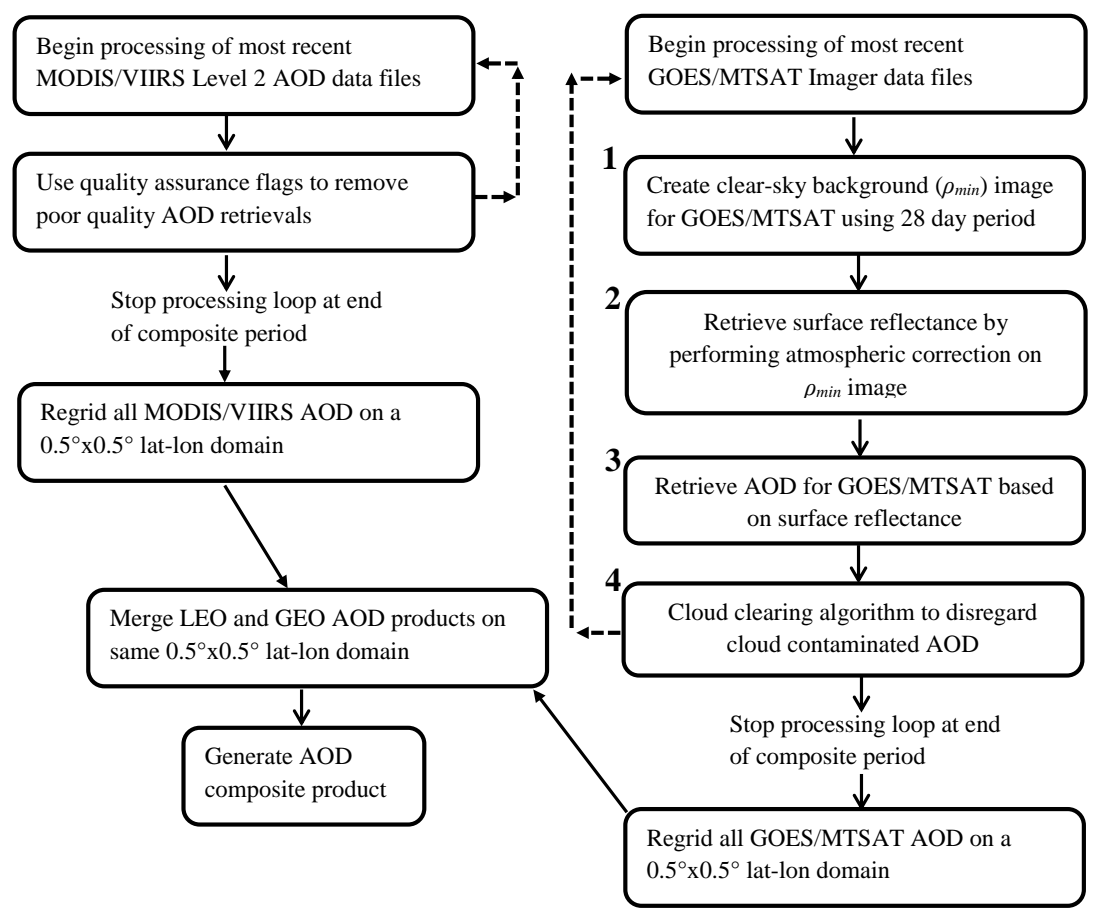

Figure 1. Schematic flow diagram of the steps involved in generating the NRT AOD composite product. The numbers 1-4 on the right-hand side of the schematic highlight the four major steps involved in the GEO AOD retrieval algorithms.

$550 \mathrm{~nm}$ introduces an additional uncertainty of 0 to $10 \%$ (Eck et al., 1999). At the time of this study, Level 2.0 data are not available at a number of AERONET stations across East Asia; therefore, we utilize the Level 1.5 cloud-screened data for these particular stations.

\subsection{MISR}

We also utilize AOD retrievals from the Multi-angle Imaging SpectroRadiometer (MISR) on board the Terra satellite to compare against the NRT AOD composite product. The MISR instrument observes the Earth in four spectral bands $(0.446,0.557,0.671,0.866 \mu \mathrm{m})$ and has nine cameras operating at nine different angles, four in forward, four in backward, and one in nadir direction. Its swath width is about $360 \mathrm{~km}$ (Diner et al., 2002), and due to the narrow swath width, near global coverage is obtained in $8-9$ days at the equator and 2 days near the poles. The relevant MISR data set for this paper is the Level 2 aerosol data (MIL2ASAE) containing AOD at four spectral channels. A detailed description of the aerosol algorithm is given in Kahn et al. (2005). MISR AOD data over ocean were found to be positively biased by about 0.04 when validated against surface-measured AODs via the Maritime Aerosol Network (MAN)(Witek et al., 2013). In order to compare against the NRT AOD composite product, the MISR $0.557 \mu \mathrm{m}$ AOD at $17.6 \mathrm{~km}$ spatial resolution has been gridded to $0.5^{\circ} \times 0.5^{\circ}$ resolution.

\subsection{CALIPSO}

The Cloud-Aerosol Lidar and Infrared Pathfinder Satellite Observations (CALIPSO) carries the active CALIOP instrument that emits pulses of light at 532 and $1064 \mathrm{~nm}$ to produce vertical profiles of the atmosphere (Winker et al., 2003). CALIOP has the unique ability to measure aerosols above clouds; therefore, we use the Level 1B 532 attenuated backscatter profiles to help confirm areas of high AOD among clouds in the AOD composite product. In addition, CALIOP measures the altitude where aerosols are located in the atmosphere, which we use as an input into the NOAA Hybrid Single-Particle Lagrangian Integrated Trajectory Model (HYSPLIT) to forecast the transport path of Asian aerosols. Note that AERONET, MISR, and CALIOP data are only used to help validate our AOD composite product. In other words, AOD retrievals from these instruments are completely independent of our product.

\section{Methodology}

The schematic flow diagram in Fig. 1 shows the steps involved in generating the NRT AOD composite product. In this section, we discuss each of these steps, but place much of the focus on the four major steps involved in the MTSAT and GOES AOD retrieval algorithms (right side of Fig. 1). 


\subsection{Clear-sky background image}

In order to effectively describe the MTSAT and GOES retrieval algorithms, we present an example of how AOD is retrieved for a MTSAT-2 image on 18 March 2014 at 05:00 UTC when a polluted dust plume was being transported over the Yellow Sea and Sea of Japan. For the MTSAT-2 imager visible data, we must convert the nominal reflectance $\left(\rho_{\text {nom }}\right)$ to a calculated reflectance using the monthly linear regression coefficients provided by the Meteorological Satellite Center of JMA. Reflectance measured by a satellite sensor is the fraction or percentage of the incoming solar radiation that is reflected or scattered by the surface and

$\rho_{\text {sat }}(\%)=\frac{\left(C_{0}+C_{1} \times \rho_{\text {nom }}\right) \times d^{2}}{\cos \left(\theta_{0}\right)} \times 100 \%$

atmosphere back towards the satellite. Equation (1) shows how the $\rho_{\text {nom }}$ (unitless) is converted to the calculated or satellite reflectance $\left(\rho_{\text {sat }}\right)$ in percentage where $C_{0}$ and $C_{1}$ are the unitless intercept and slope linear regression coefficients, $d$ is the Earth-Sun distance in astronomical units, and $\theta_{0}$ is the solar zenith angle. The linear regression coefficients for March 2014 are 1.2257 and -0.0006 for $C_{0}$ and $C_{1}$, respectively. The first step of the MTSAT AOD retrieval algorithm is to gather visible imagery data at 05:00 UTC beginning 19 February through 18 March (28 total) and calculate $\rho_{\text {sat. }}$. Then, we find the second lowest $\rho_{\text {sat }}$ for each pixel during the 28-day period, which generates the clearsky background $\left(\rho_{\min }\right)$ image. The same approach is taken to generate the $\rho_{\min }$ for the GOES-15 imager except that the $\rho_{\text {sat }}$ is calculated based on calibration coefficients provided by the NOAA NESDIS Center for Satellite Applications and Research (STAR). Note that we chose the 28-day period after conducting sensitivity tests using 21-, 24-, 28-, and 35-day periods, which is discussed in Sect. 5. Although our sensitivity tests indicated that 28 days is the optimal period, the variation in solar geometry throughout the 4-week period can still lead to considerable uncertainties, especially at lower surface reflectances.

\subsection{Surface reflectance $\left(\boldsymbol{R}_{\mathrm{sfc}}\right)$ retrieval}

For the second step, we retrieve the surface reflectance $\left(R_{\text {sfc }}\right)$ by removing the atmospheric effects from the $\rho_{\min }$ image via a look-up table $\left(\mathrm{LUT}_{\mathrm{sfc}}\right)$. The $\mathrm{LUT}_{\text {sfc }}$ is generated using the Version 1.1 of the Second Simulation of a Satellite Signal in the Solar Spectrum Vector (6SV) radiative transfer model (RTM) (Kotchenova et al., 2006; Kotchenova and Vermote, 2007) 6SV code. The highly accurate 6SV code contains the same atmospheric correction procedure used by the MODIS team (Vermote and Kotchenova, 2008). However, in developing the $\mathrm{LUT}_{\mathrm{sfc}}$, we are required to make some assumptions regarding the state of the atmosphere throughout the $\rho_{\min }$ image. First, in order to remove the atmospheric effects, we used temperature, water vapor, and ozone information from the US standard profiles already available in the 6SV code. Our sensitivity tests in Sect. 5.1 show that using US standard profiles causes uncertainties in AOD of less than $1 \%$, which agrees with the findings of Levy et al. (2013). Second, we assume a background AOD of 0.05 since the visible bands on board the MTSAT-2 and GOES-15 satellites have been shown to be insensitive to low concentrations of AOD (Knapp et al., 2005). After making these assumptions, the $6 \mathrm{SV}$ code is used to simulate the top of atmosphere reflectance $\left(\rho_{\text {toa }}\right)$ values for a range of $16 \theta_{0}, 16$ viewing zenith angles $(\theta), 15 \varphi$, and $8 R_{\text {sfc }}$ (i.e., $L T_{\text {sfc }}$ ). We search the $\mathrm{LUT}_{\text {sfc }}$ for the solar/satellite geometry that most closely matches that for each pixel in the MTSAT- 2 and GOES-15 imager scan. After identifying the solar/satellite geometry match, we retrieve the $R_{\text {sfc }}$ for each pixel by interpolating $\rho_{\min }$ to the simulated $\rho_{\text {toa }}$ values. Figure 2a displays the MTSAT- 2 imager $\rho_{\text {sat }}$ on 18 March 2014, where a plume of dust and pollution extending from China to over the Sea of Japan trails behind a frontal band associated with a lowpressure system near Japan. The $R_{\mathrm{sfc}}$ retrievals for each pixel in the MTSAT- 2 imager scan are shown in Fig. $2 b$ where we only retrieve the $R_{\mathrm{sfc}}$ when the $\theta_{0}$ and $\theta$ is less than $70^{\circ}$ as AOD retrievals at larger angles are associated with significant uncertainty (e.g., Ignatov and Stowe, 2002). Additionally, AOD is not retrieved for the pixels highlighted in red $\left(R_{\mathrm{sfc}}>35 \%\right)$, since they are likely contaminated with either cloud, snow, or ice. However, we are able to attempt an AOD retrieval for the majority of the pixels in the $R_{\text {sfc }}$ image as most of the scene appears to be uncontaminated.

\subsection{AOD retrieval}

The third step consists of retrieving the GOES and MTSAT AOD via additional LUTs, which are created similarly to $\mathrm{LUT}_{\text {sfc }}$ except that we use the $6 \mathrm{SV}$ code to simulate the $\rho_{\text {toa }}$ for seven different AODs in addition to the range of $\theta_{0}, \theta$, $\varphi$, and $R_{\mathrm{sfc}}$ used in creating $\mathrm{LUT}_{\mathrm{sfc}}$. The most significant assumption in creating these LUTs is the selection of the aerosol model, as the simulated $\rho_{\text {toa }}$ can vary greatly based on the optical properties of the aerosols. Thus, prior to selecting an aerosol model for our domain, we conduct a detailed comparison between the observed $\rho_{\text {sat }}$ and simulated $\rho_{\text {toa }}$ using seven different $6 \mathrm{SV}$ aerosol models for 24 unique cases occurring over AERONET stations across eastern Asia during March and April 2014. Overall, this comparison showed that selecting the 6SV continental and desert aerosol models would introduce the least amount of uncertainty compared to the other aerosol models available in the code, which is discussed in Sect. 5.3. Therefore, to represent these aerosol models we create two separate LUTs for retrieving AOD,

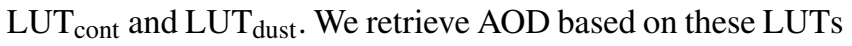
by using the $R_{\text {sfc }}$ from the surface reflectance retrieval step and then interpolating $\rho_{\text {sat }}$ to the simulated $\rho_{\text {toa }}$ values to retrieve the AOD. Note that we do not invoke the $\mathrm{LUT}_{\text {dust }}$ unless a pixel passes a handful of dust detection techniques that 

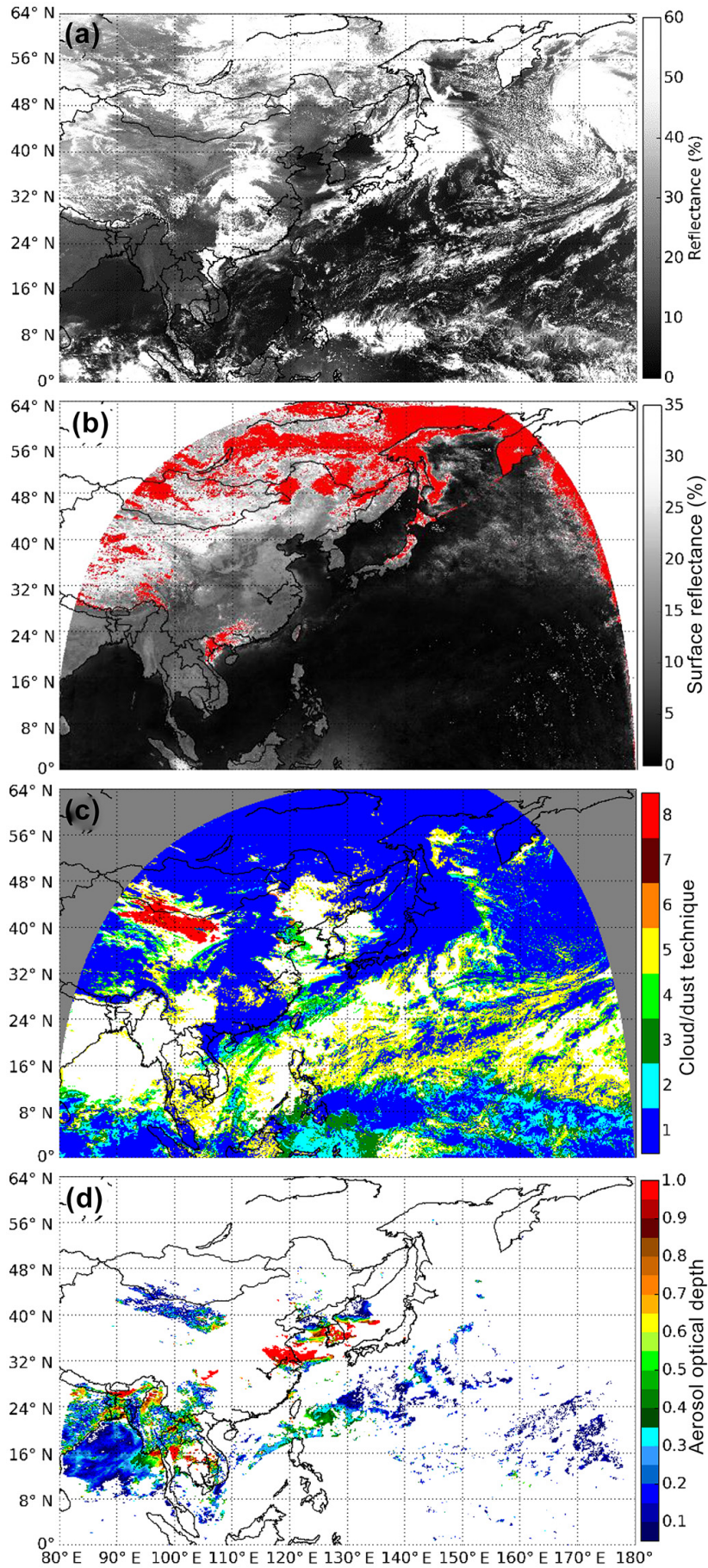

Figure 2. All panels pertain to 18 March 2014 at 05:00 UTC. (a) MTSAT-2 imager $0.68 \mu \mathrm{m}$ reflectance scan. (b) $\mathrm{R}_{\mathrm{sfc}}$ retrievals for each valid pixel in MTSAT-2 imager scan where pixels with $\mathrm{R}_{\mathrm{sfc}}$ $>35 \%$ are denoted in red. (c) Cloud/dust detection results where the color bar labels relate to technique no. in Table 3. (d) MTSAT AOD retrievals. are explained in Sect. 3.4. In addition, separate LUTs were generated for the visible bands of the MTSAT- 2 and GOES15 imagers due to having unique spectral response functions. The spectral response functions for the visible bands on board these satellites were not available in the 6SV1.1 RTM; therefore, we updated the $6 \mathrm{SV}$ source code to account for these bands prior to producing the LUTs.

\subsection{Cloud and dust detection}

For the fourth and final step of the MTSAT and GOES retrieval algorithms, we use cloud and dust detection procedures to disregard contaminated AOD retrievals and identify any pixels influenced by dust. Developing accurate cloud detection algorithms for these GEO satellites is not a trivial step due to their lower spatial resolution and limited number of spectral bands. In an effort to obtain as much information as possible from four spectral bands $(6.7 \mu \mathrm{m}$ water vapor band is not used), we extract reflectance and temperature from the $3.9 \mu \mathrm{m}$ band based on Mecikalski et al. (2010). Then, we use spectral, spatial, and temporal techniques based on the reflectance and temperature information from the four spectral bands to identify clouds and dust in each satellite image. The cloud/dust detection techniques for these satellites are similar, even though the GOES imager has a $13.3 \mu \mathrm{m}$ band instead of the $12.0 \mu \mathrm{m}$ band on board MTSAT. However, we were able to develop more sophisticated dust detection techniques for MTSAT, as dust particles have a larger imaginary index of refraction at $10.8 \mu \mathrm{m}$ compared to $12.0 \mu \mathrm{m}$, while most other aerosol and cloud types show an opposite trend (Ackerman, 1997). This can influence a negative difference between the 10.8 and $12.0 \mu \mathrm{m}$ bands, which can be used to identify dust aerosols (Sokolik, 2002; Naeger et al., 2013b). In this paper, we will only briefly step through the MTSAT cloud/dust detection procedure (Table 3), but will note any important differences that arise in the GOES procedure. The techniques shown in Table 3 were developed after close examination of dozens of MTSAT satellite images involving cloud and aerosols throughout the year 2014. Thus, this procedure can be applied during any season, but note that it will generally overestimate cloud coverage, as its main purpose is to prevent subpixel cloud contamination and cloud adjacency effects from impacting the AOD retrievals. The spatial techniques help greatly with disregarding AOD retrievals impacted by these cloud effects over both land and ocean, but they work especially well over the homogeneous ocean surface where the thresholds for cloud detection were able to be set to lower values. Note that we also detect and screen out all possible sunglint-affected pixels during this step.

Figure $2 \mathrm{c}$ shows the overall results of the cloud/dust procedure for $\theta_{0}$ and $\theta<75^{\circ}$ on 18 March 2014 at 05:00 UTC. We run the procedure in the same order as shown in Table 3. After passing one of the spectral, spatial, or temporal techniques, the pixel is immediately labeled as cloudy using the corresponding number in the right-hand column. A 
Table 3. MTSAT cloud clearing algorithm with the various techniques and thresholds in the left column; the center column shows the conditions when the techniques are used, and the technique no. relating to cloud/dust detection algorithm results in Fig. $2 \mathrm{c}$ is in the right column. The "time" subscript indicates a temporal technique.

\begin{tabular}{lll}
\hline \multicolumn{1}{c}{ MTSAT cloud/dust detection algorithm } & \\
\hline Techniques & Condition & No. \\
\hline Spectral techniques & & \\
$3.8-0.68 \mu \mathrm{m}<-20 \%$ & Land/water & 1 \\
$3.8-12.0 \mu \mathrm{m}>25 \mathrm{~K}$ & Land & 2 \\
$3.8-12.0 \mu \mathrm{m}>12 \mathrm{~K}$ & Water & 2 \\
$10.8-12.0 \mu \mathrm{m}>2.0 \mathrm{~K}$ and $3.8-10.8 \mu \mathrm{m}>2.0 \mathrm{~K}$ & Water & 3 \\
Spatial techniques & & \\
$3 \times 3 \sigma 10.8 \mu \mathrm{m}>4.0 \mathrm{~K}$ or $3 \times 3 \sigma 12.0 \mu \mathrm{m}>4.0 \mathrm{~K}$ & Land & 4 \\
$3 \times 3 \sigma 10.8 \mu \mathrm{m}>1.0 \mathrm{~K}$ or $3 \times 3 \sigma 12.0 \mu \mathrm{m}>1.0 \mathrm{~K}$ & Water & 4 \\
$3 \times 3 \sigma 0.68 \mu \mathrm{m}>3.0 \%$ or $5 \times 5 \sigma 0.68 \mu \mathrm{m}>3.0 \%$ & Land & 5 \\
$3 \times 3 \sigma 0.68 \mu \mathrm{m}>1.5 \%$ or $5 \times 5 \sigma 0.68 \mu \mathrm{m}>1.5 \%$ & Water & 5 \\
Temporal techniques & & \\
$10.8 \mu \mathrm{m}_{\text {time }}>3.0 \mathrm{~K}$ or $12.0 \mu \mathrm{m}_{\text {time }}>3.0 \mathrm{~K}$ & Water & 6 \\
$10.8 \mu \mathrm{m}_{\text {time }}>10.0 \mathrm{~K}$ and $12.0 \mu \mathrm{m}_{\text {time }} / 10.8 \mu \mathrm{m}_{\text {time }}>1.0 \mathrm{~K}$ & Land & 6 \\
Dust techniques & & \\
$10.8-12.0 \mu \mathrm{m}<-1.0 \mathrm{~K}$ & Cloud & 7 \\
$3 \times 3 \sigma 0.68 \mu \mathrm{m}<4.0 \% \& 5 \times 5 \sigma 0.68 \mu \mathrm{m}<4.0 \%$ & Cloud & 7 \\
$3.8-10.8 \mu \mathrm{m}>4.0 \mathrm{~K}$ & Cloud & 7 \\
$12.0 \mu \mathrm{m}>258 \mathrm{~K}$ & Cloud & 7 \\
$10.8-12.0 \mu \mathrm{m}<=-0.5 \mathrm{~K}$ or $\mathrm{Rsfc}>20 \%$ & Cloud-free & 8 \\
\hline
\end{tabular}

pixel must fail all the cloud detection techniques to be labeled cloud-free. We only retain AOD retrievals that are associated with cloud-free pixels. Approximately $80 \%$ of the valid MTSAT pixels are labeled as cloud and the spectral techniques detect about $71 \%$ of these clouds. Spectral technique no. 3 does not appear in the GOES cloud/dust procedure due to the absence of the $12.0 \mu \mathrm{m}$ band. The spatial techniques detect a significant fraction of the remaining clouds $(\sim 28 \%)$, especially in regions of scattered cumulus clouds over the ocean. Although the impact of the temporal techniques appears very minimal in Fig. 2c, they are able to detect some lingering clouds (e.g., $\sim 40^{\circ} \mathrm{N}, 120^{\circ} \mathrm{E}$ ) that could lead to artifacts in the NRT AOD composite product.

Since possible dust regions can be mislabeled as cloud by our procedure due to their similar spectral characteristics, we use four dust techniques to locate pixels mislabeled as cloud and relabel them as cloud-free. The special techniques were developed based on the fact that dust regions can have strong positive $3.8-10.8 \mu \mathrm{m}$ values similar to clouds, but are often more homogeneous than clouds while influencing 10.8$12.0 \mu \mathrm{m}$ values less than $-1^{\circ}$ Kelvin. A considerable number of pixels are relabeled as cloud-free in northern China. The final dust technique in Table 3 operates only on cloudfree pixels. If a pixel passes this technique, then the AOD is revised based on the LUT $_{\text {dust }}$ instead of the $\mathrm{LUT}_{\text {cont }}$ that was assumed for each pixel during the third step. Although similar to MTSAT, the GOES dust detection technique is not as robust as the $10.8-12.0 \mu \mathrm{m}$ test cannot be included in the GOES technique due to the absence of the $12.0 \mu \mathrm{m}$ band. After applying the cloud/dust detection procedure, we arrive at our final cloud-cleared AOD map for this MTSAT imager scan at 05:00 UTC on 18 March (Fig. 2d). The map shows high AOD $>1.0$ associated with the thick pollution and dust plume propagating from eastern Asia to over the Pacific Ocean. Pollution and smoke plumes are also causing high AOD in regions across southern Asia. Thus, we are able to depict some features on this AOD map, but the large gaps in coverage due to clouds make it difficult to fully understand the spatial distribution of aerosols.

\subsection{LEO AOD products}

While retrieving AOD from the GEO imager data, we also process the Aqua and Terra MODIS AOD via the NASA LANCE data system and VIIRS AOD via the NOAA CLASS service (left side of Fig. 1). To help prevent poor-quality MODIS AOD from being introduced into our AOD composite maps, we use the MODIS cloud fraction parameter and quality assurance flags to ignore retrievals associated with marginal confidence and cloud cover $>70 \%$. We disregard poor-quality VIIRS AOD by using the quality flags to ignore retrievals where at least one pixel among the $8 \times 8$ pixel region is cloud- or cirrus-contaminated. 


\subsection{NRT AOD composites}

In order to generate the NRT AOD composites, we use all the valid GEO and LEO AOD data that were processed over a $24 \mathrm{~h}$ period beginning 12:00 UTC each day. At the end of the $24 \mathrm{~h}$ AOD composite period, AOD data from the GEO and LEO sensors are regridded and averaged onto a common domain with $0.5^{\circ} \times 0.5^{\circ}$ spatial resolution centered over the central Pacific Ocean in order to effectively track the transPacific transport of aerosols. The rather coarse $0.5^{\circ} \times 0.5^{\circ}$ grid is suitable for our particular application where larger scale, more homogeneous aerosol plumes are the focus. We use a nearest neighbor approach to find and calculate the average of all AOD retrievals for each GEO imager that fall within each grid box. This same operation is performed for the LEO AOD retrievals. These GEO and LEO AOD composite maps are then merged together to generate the final daily AOD composite maps. When merging these composite maps, the LEO AOD is chosen to represent a grid box when both LEO and GEO AOD are available due to the higher uncertainty associated with the GEO retrievals.

In our current methodology, we do not apply techniques to account for the differences in observation times or spatial resolutions between the GEO and LEO sensors, which may lead to undesirable jumps in AOD when merging the different sensors on a common grid. However, according to the case in Sect. 4, our simplified approach does not lead to frequent AOD jumps in our daily composite product.

\section{Results}

\subsection{March 2014}

The top three panels in Fig. 3 display the daily AOD composites for the case study on 18 March 2014. The central time of the AOD composite product is 00:00 UTC, since we used satellite information between 12:00 UTC on 17 March and 12:00 UTC on 18 March to generate the product. Figure 3a is an example of the daily AOD composite with only GEO (i.e., MTSAT/GOES) retrievals, while Fig. $3 b$ is an example with only LEO (i.e., MODIS/VIIRS) retrievals. All these satellite retrievals are combined onto the same map to generate the final version of the daily AOD composite product, which shows a more complete picture of the spatial distribution of aerosols during this $24 \mathrm{~h}$ period (Fig. 3c). A massive aerosol plume extends from eastern China to almost the central Pacific region as moderate AOD of approximately 0.6 is identified around $38^{\circ} \mathrm{N}, 165^{\circ} \mathrm{E}$. Aerosols with moderate AOD of around 0.6 are still propagating from the central China region behind the extensive cloud feature in the MTSAT $0.68 \mu \mathrm{m}$ image, suggesting that poor air quality and visibility may plague eastern China in the short term. A fairly extensive aerosol plume is moving from southeast China to the tropical Pacific around $20^{\circ} \mathrm{N}, 120^{\circ} \mathrm{E}$, while aerosol layers with AOD $>0.5$ are impacting much of Southeast Asia $\left(\sim 15^{\circ} \mathrm{N}\right.$, $\left.100^{\circ} \mathrm{E}\right)$. It is important to note that the GEO retrievals blend into Fig. 3c rather well due to the overall good agreement in the spatial patterns of AOD between Fig. 3a and b. For example, the aerosol plume moving from Southeast China to the tropical Pacific is not fully represented using LEO AOD retrievals alone. Fortunately, the MTSAT retrievals fill this region with AOD that blends in very well with the surrounding LEO AOD. Additionally, the massive aerosol plume from eastern China is more fully represented in Fig. 3c than in Fig. 3b, since MTSAT is able to observe additional cloudfree regions among the plume.

Although the spatial patterns of AOD compare fairly well between Fig. 3a and b, some important differences exist between the maps. First, the LEO sensors are capable of providing AOD retrievals among broken clouds in the midlatitudes, while the GEO sensors generally provide a minimal number of AOD retrievals in these regions, which is tied to the much finer spatial resolution of the LEO sensors $(<1 \mathrm{~km}$ at nadir for the LEO sensors and $>4 \mathrm{~km}$ at nadir for the GEO sensors). This is highlighted by the 18 March case where the LEO sensors provide numerous AOD retrievals among the area of broken clouds around $38^{\circ} \mathrm{N}, 165^{\circ} \mathrm{E}$ while the MTSAT sensor is unable to identify any cloud-free AOD retrievals. Note this region is not within the viewing range of GOES. Second, the GEO retrievals tend to be biased low in regions where cloud cover influences overestimations in the $R_{\text {sfc }}$ retrievals (Fig. 2b). Clouds tend to impact the $R_{\text {sfc }}$ retrievals more often in the North and central Pacific due to the decrease in spatial resolution of the GEO sensors. This is apparent around $30^{\circ} \mathrm{N}, 137^{\circ} \mathrm{E}$ in Fig. $3 \mathrm{a}$ and $\mathrm{b}$ where MTSAT AOD is about 0.2 lower than the LEO AOD. The comparison to MISR AOD in this same region suggests that the LEO AOD retrievals are more accurate as they are generally within \pm 0.05 of MISR, while the MTSAT retrievals are 0.05 to 0.2 lower than MISR. Note that MISR retrievals are strictly for intercomparison purposes and completely independent of the AOD composite product. Third, the GEO AOD retrievals are more prone to cloud contamination compared to the LEO retrievals, which can lead to high biases in AOD. For example, there is a general high bias in GEO AOD over the tropical Pacific in Fig. 3a due to cloud contamination influencing the retrievals. This is especially evident over parts of Indonesia $\left(\sim 2^{\circ} \mathrm{N}, 115^{\circ} \mathrm{W}\right)$ where MTSAT AOD $>1.0$, while LEO AOD < 0.4. MISR is void of AOD in this same region due to the extensive cloud cover. Lastly, there are large discrepancies between the AOD across Southeast Asia as indicated by the MISR overpass around $15^{\circ} \mathrm{N}, 107^{\circ} \mathrm{E}$ where the GEO and LEO AOD retrievals are as much as 0.6 and 0.3 higher than MISR, respectively. The highly uncertain AOD retrievals are attributed to the complex terrain of Southeast Asia along with the scattered cloud coverage on this day.

The CALIPSO made several transects directly over the aerosol plumes across the western Pacific and eastern Asia on 18 March. We analyze the CALIPSO transects indicated in Fig. 3c (black lines) from east to west. Figure 4a 


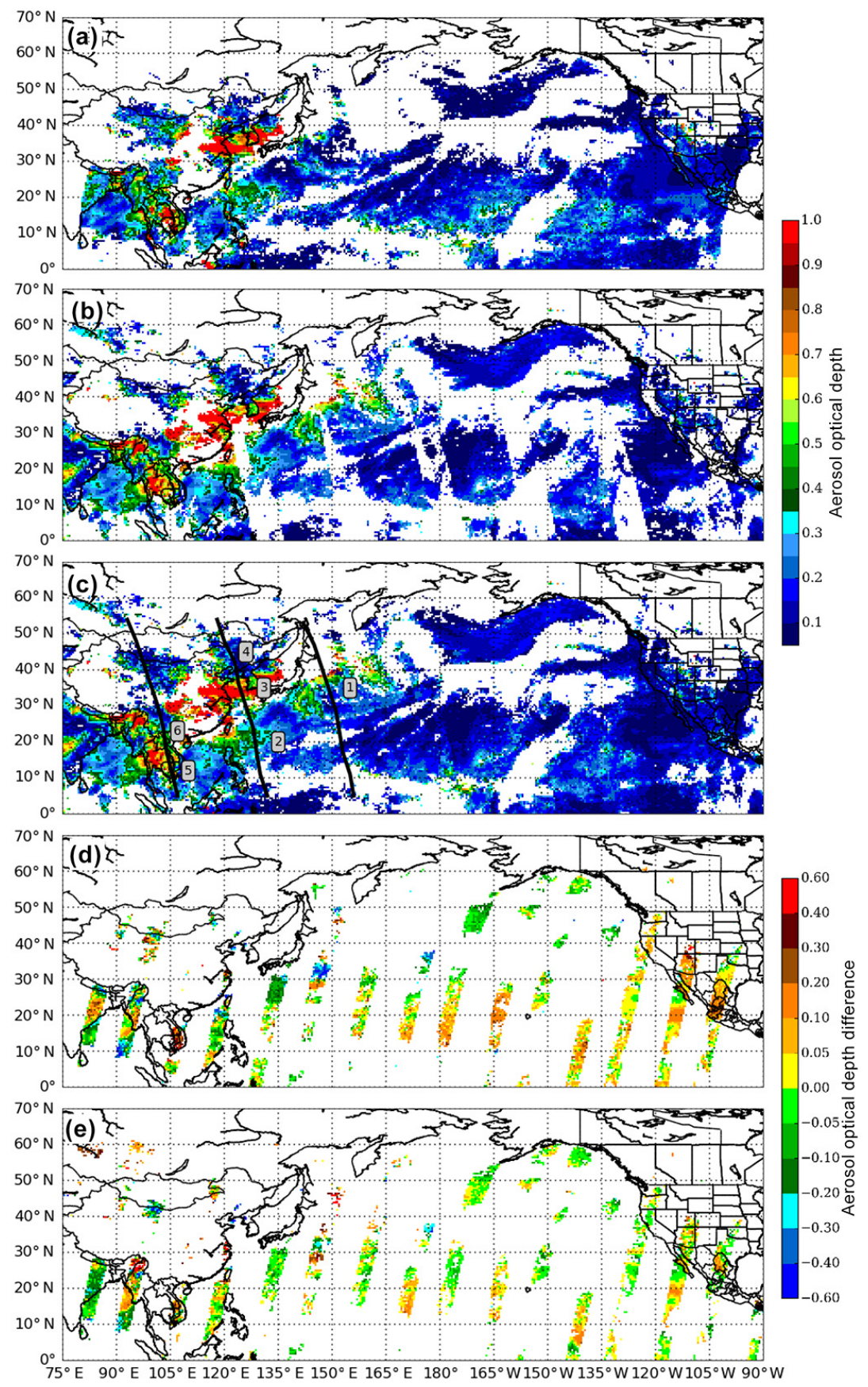

Figure 3. The top three panels display the daily AOD composites with central time at 00:00 UTC on 18 March 2014. (a) Example of the daily AOD composite when only GEO retrievals are utilized, (b) example of when only LEO retrievals are utilized, (c) final version of our daily AOD composite product that combines all satellite retrievals onto the same map. (d) Difference plot between the GEO AOD retrievals and the available MISR AOD retrievals during the $24 \mathrm{~h}$ period. (e) Difference plot between LEO AOD retrievals and MISR AOD.

shows the $532 \mathrm{~nm}$ attenuated backscatter profiles from about 03:20 UTC on 18 March where moderate backscatter values are measured from an aerosol plume at approximately $3 \mathrm{~km}$ in height (box 1). The CALIOP Vertical Feature Mask (VFM) and aerosol subtype browse images confirmed this region of moderate backscatter as aerosol consisting of dust and polluted dust. This aerosol layer is likely interacting with the high, thick clouds to the north in Fig. 4a. The daily AOD composite product (Fig. 3c) reveals moderate to high AOD in the vicinity of this aerosol layer. Several noteworthy aerosol plumes are measured by CALIOP during the transect at about 05:00 UTC (Fig. 4b). First, moderate backscat- 

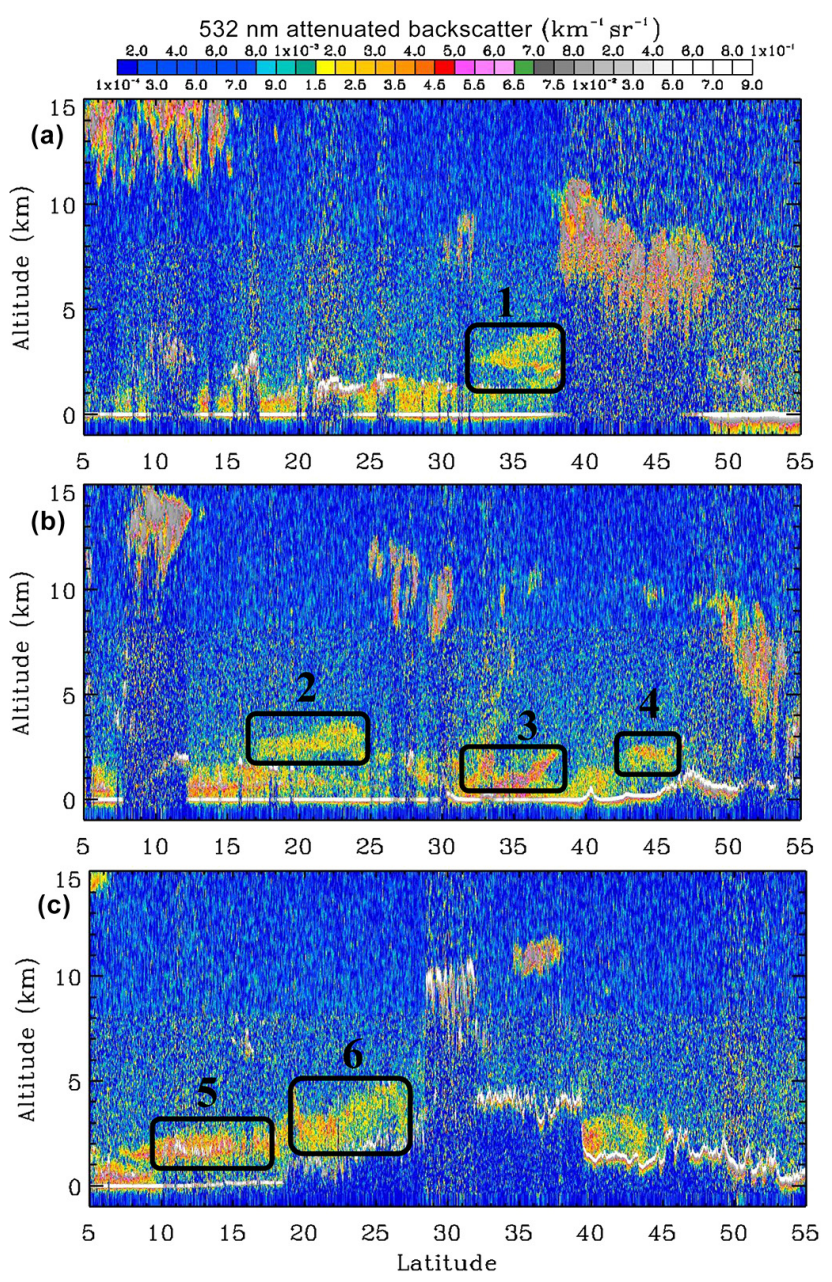

Figure 4. All panels show CALIOP $532 \mathrm{~nm}$ attenuated backscatter profiles on 18 March 2014. CALIPSO transects are indicated in Fig. 4c (black lines), which are increasing in time from east to west with (a) at about 03:20 UTC, (b) at about 05:00 UTC, and (c) at about 06:40 UTC. Boxes highlight regions of interest. The locations of these boxes along the CALIPSO transects are also indicated in Fig. 4c.

ter values are associated with an aerosol layer from about $18-24^{\circ} \mathrm{N}$ (box 2). Even though the CALIPSO transect shows scattered low clouds residing beneath much of the aerosol layer, the AOD composite is still able to depict AOD ranging from 0.3 to 0.7 in this same area. Next, CALIOP measures very strong backscatter signals from the aerosol region in box 3, which is clearly shown in the composite product by the large area of AOD $>1$. The CALIOP aerosol subtype algorithm labels this aerosol region as a mixture of dust and polluted dust. Finally, CALIOP measures moderate backscatter from a fairly thin aerosol plume mixed with smoke and polluted dust in box 4. A close inspection of the AOD composite reveals a confined area of AOD $\sim 0.3$ in the vicinity of the aerosol plume. A couple of hours later at about 06:40 UTC CALIPSO flew directly over the very compli- cated scene of Southeast Asia (Fig. 4c), consisting of clouds located within an aerosol layer (box 5) and then aerosols above terrain features (box 6). The CALIOP VFM image revealed that portions of the aerosol layer in box 5 were cloudfree, particularly near $10^{\circ} \mathrm{N}$. CALIOP measures moderate to high backscatter in these cloud-free regions, which suggests that the AOD composite values from 0.5 to 1.0 across this region represent the aerosol layers rather well. Thus, it is very likely that MISR is severely underestimating the AOD in this region, while the LEO and MTSAT AOD retrievals are performing much better. Lower backscatter is measured by CALIOP over the terrain features in box 6 , and the AOD composite shows lower AOD ranging from 0.4 to 0.5 in this same area. Overall, the CALIPSO transects indicate that our AOD composite realistically represents the intensity of the aerosol plumes throughout the western Pacific and Asia.

\subsection{HYSPLIT trajectory analysis}

We investigate the transport pathways for three of the aerosol plumes identified in the CALIOP $532 \mathrm{~nm}$ attenuated backscatter profiles (boxes 1, 2, and 5) through the online HYSPLIT tool from NOAA Air Resources (http://ready.arl. noaa.gov/HYSPLIT.php) (Rolph, 2016) to calculate the forward trajectories of air parcels. Note that these trajectory calculations do not account for aerosol particulate transport processes, such as sedimentation and wet and dry deposition, which can influence aerosol pathways, especially during long-range transport events. We run HYSPLIT for an ensemble of 27 trajectories from each aerosol plume location for a $96 \mathrm{~h}$ period beginning at 05:00 UTC on 18 March until that same time on 22 March using National Centers for Environmental Prediction (NCEP) reanalysis meteorological data. The CALIOP attenuated backscatter profiles are used to estimate the altitudes of the three aerosol plumes, which are all around $3 \mathrm{~km}$. The start altitude of the trajectory simulations is a necessary input that must be given to the NOAA HYSPLIT model when making these simulations. Figure 5 shows that nearly all the HYSPLIT trajectories initialized from position 1 (box 1) propagate the polluted dust plume to over the far eastern extent of the Pacific Ocean or over the Pacific Northwest by 22 March at 05:00 UTC. This dust/pollution plume is an excellent example of a typical trans-Pacific transport pathway via the midlatitude westerly winds (Wilkening et al., 2000). The ensemble of trajectories initialized from position 2 (box 2) suggests that the aerosol plume is likely to move westward. A handful of trajectories show the plume moving slowly eastward, but they never make any significant headway toward North America by the end of the 4-day period. All the trajectories initialized from position 5 (box 5) located over Southeast Asia took the aerosol plume south and west of the initial position. Consequently, the possible discrepancies in AOD that can appear over Southeast Asia are not considered a significant problem when using the AOD composites to track the trans-Pacific transport of aerosols. 


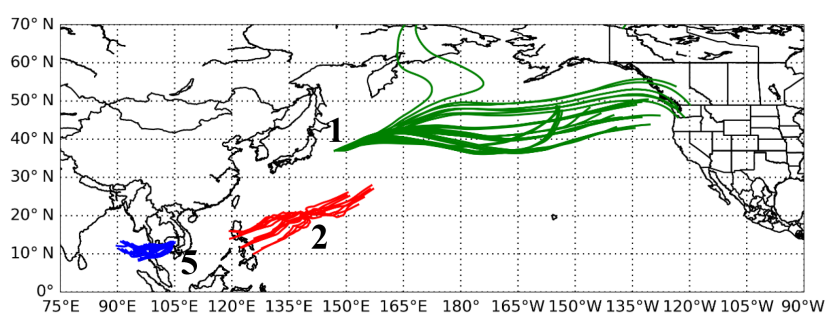

Figure 5. NOAA HYSPLIT model forward trajectory results for the 4-day time period beginning 18 March 2014 at 05:00 UTC. We initialize the model from locations 1, 2, and 5 along the CALIPSO transects in Fig. 5. CALIOP aerosol height information at these locations is also used to initialize the model.

\subsection{March 2014}

To confirm whether this polluted dust plume reached the western coast of North America, we generated the daily AOD composite with a central time of 00:00 UTC on 23 March shown in Fig. 6c. The daily AOD composite depicts moderate AOD of 0.4 to 0.5 over the extreme eastern Pacific, which suggests that remnants of the plume in the western Pacific experienced trans-Pacific transport. However, the majority of the HYSPLIT ensemble runs predict the aerosol plume to be further east than shown in the AOD composite with a handful of runs showing the plume over western North America by 22 March at 05:00 UTC. These differences in aerosol plume location between the ensemble runs and the AOD composite are likely attributed to the fact that the online HYSPLIT tool does not account for the sedimentation and deposition of aerosol particles. This case study shows the utility of the AOD composites for model validation and the potential benefit of using the composites for model assimilation.

The overall results in Fig. 6 are similar to those shown for the 18 March case. Again, the GEO retrievals in Fig. 6a are generally in close agreement to the LEO retrievals in Fig. 6 b. Thus, the AOD composite product in Fig. 6c shows a robust spatial distribution of aerosols without encountering anomalous jumps in AOD between adjacent grid boxes. Many of the same features are revealed on the GEO and LEO AOD maps, such as the dense aerosol plume with AOD $>1.0$ over eastern Asia. However, the GEO AOD retrievals reveal areas of moderately thick aerosols over northern China $\left(\sim 40^{\circ} \mathrm{N}, 106^{\circ} \mathrm{E}\right)$ that are not indicated by the LEO retrievals. A nighttime CALIPSO transect on 23 March at about 19:00 UTC (not shown) measured a fairly large region of moderate backscatter from dust aerosols over this same region in northern China, which suggests that the MTSAT AOD of about 0.5 is representative of the aerosol conditions. Furthermore, the GEO sensors appear to be encountering similar issues as discussed for the 18 March case. For instance, the transported dust plume over the extreme eastern Pacific $\left(\sim 50^{\circ} \mathrm{N}\right.$, $\left.135^{\circ} \mathrm{W}\right)$ is poorly represented on the GEO AOD map due to the much lower spatial resolution of the GEO sensors com-
Table 4. The AOD coverage for the individual LEO and GEO retrievals and for the daily AOD composite product (COMP). We present the coverage statistics for 6 days, including the 18 and 23 March case studies analyzed in this paper. The number of valid AOD retrievals across our AOD composite domain along with the percent coverage based on the total number of available grid boxes are shown.

\begin{tabular}{lccc}
\hline Case & $\begin{array}{c}\text { LEO coverage } \\
\text { (no. pixels/\%) }\end{array}$ & $\begin{array}{c}\text { GEO coverage } \\
\text { (no. pixels/\%) }\end{array}$ & $\begin{array}{c}\text { COMP coverage } \\
\text { (no. pixels/\%) }\end{array}$ \\
\hline $18 \mathrm{Mar}$ & $48368 / 69$ & $43906 / 62$ & $58564 / 83$ \\
$19 \mathrm{Mar}$ & $49980 / 71$ & $45023 / 64$ & $60050 / 85$ \\
$20 \mathrm{Mar}$ & $46543 / 66$ & $41348 / 59$ & $55792 / 79$ \\
$21 \mathrm{Mar}$ & $50071 / 71$ & $44998 / 64$ & $61755 / 88$ \\
$22 \mathrm{Mar}$ & $43851 / 62$ & $39004 / 55$ & $52095 / 74$ \\
$23 \mathrm{Mar}$ & $44960 / 64$ & $40540 / 58$ & $53580 / 76$ \\
Average & $47296 / 67$ & $42470 / 60$ & $56973 / 81$ \\
\hline
\end{tabular}

pared to the LEO sensors. In addition, the GEO AOD retrievals are biased high across the tropical Pacific compared to the LEO retrievals, especially in the latitude band from 10 to $20^{\circ} \mathrm{N}$ over the eastern Pacific. Nevertheless, some of the areas of elevated AOD around 0.3 depicted in the GEO map correspond well to that shown in the LEO map (e.g., $\sim 15^{\circ} \mathrm{N}$, $\left.165^{\circ} \mathrm{W}\right)$. Finally, MTSAT AOD is significantly lower than the LEO AOD along the coast of southeast China $\left(\sim 25^{\circ} \mathrm{N}\right.$, $\left.115^{\circ} \mathrm{E}\right)$ due to persistent cloud cover in this area throughout the 28-day period used to retrieve $R_{\mathrm{sfc}}$.

To quantitatively show the gain in spatial coverage due to the inclusion of the GEO sensors in our daily AOD composite maps, we calculate the number of valid AOD retrievals along with the percent coverage of those retrievals based on the total number of available grid boxes (70 400 grid boxes) across our composite domain. These statistics are calculated for the individual GEO and LEO AOD maps along with our final AOD composite maps that merge the GEO and LEO retrievals. We show statistics for a 6-day period, which includes the 18 and 23 March case studies presented in this paper (Table 4). Overall, the LEO sensors provide more spatial coverage compared to the GEO sensors (67 vs. $60 \%$ ) during this 6-day period. As shown in this paper, the higher percentage for the LEO sensors is partly due to the fact that they have better coverage throughout the northern regions of the AOD composite domain. The LEO sensors also have better coverage over the central Pacific and over the far eastern and western portions of the composite domain, which is due to the limited geographical coverage of the GEO sensors. The GEO retrieval algorithms developed in this study further limit their geographical coverage by restricting $\theta$ to less than $70^{\circ}$ to avoid the very large uncertainties that arise at these oblique angles. Although the LEO coverage is better than GEO, introducing the GEO sensors into the AOD composite maps still leads to considerable increases in spatial coverage for our final product. For the 6-day period in Table 4, the in- 


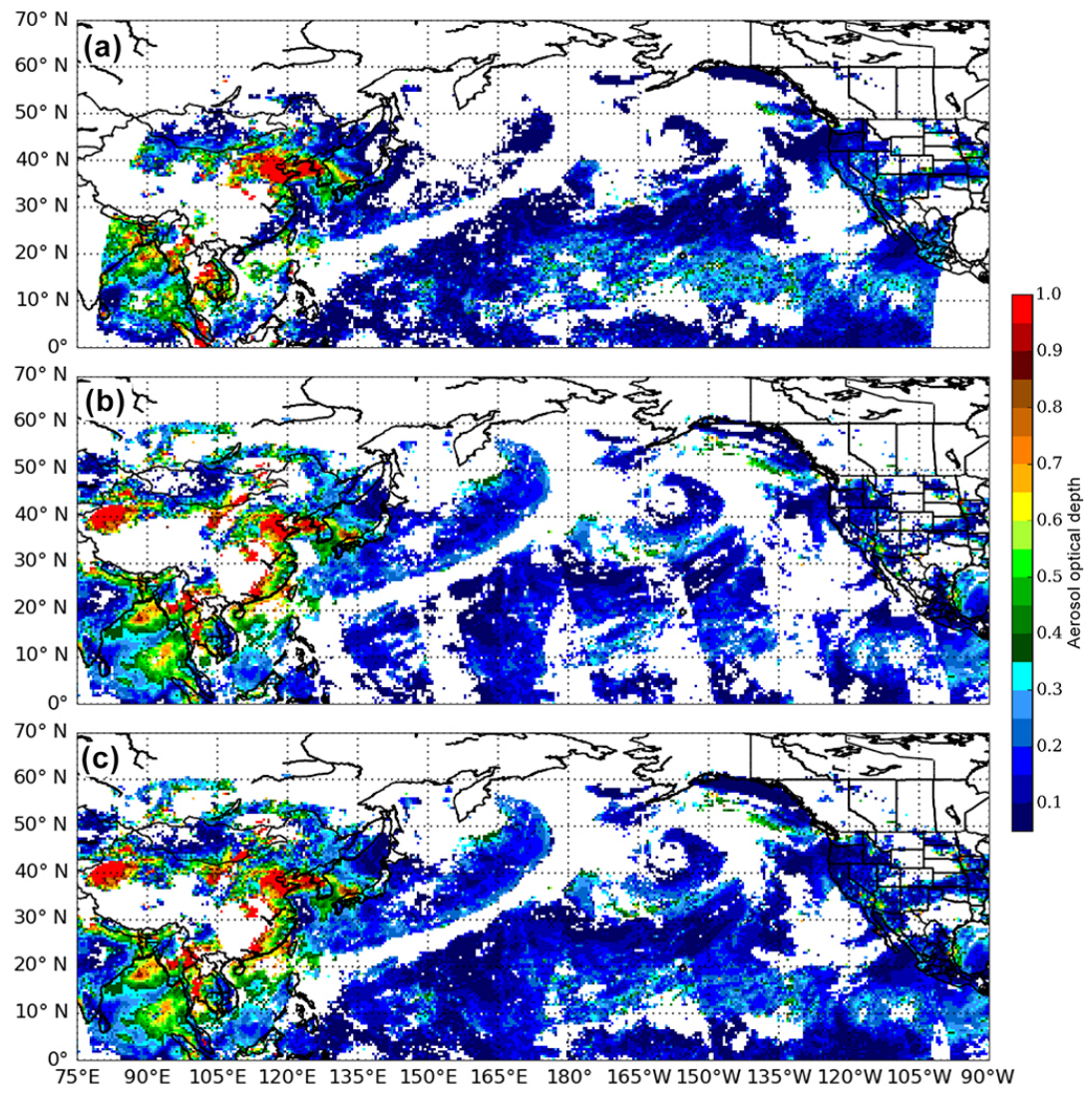

Figure 6. Panels show the daily AOD composites with central time at 00:00 UTC on 23 March 2014. (a) Example of the daily AOD composite when only GEO retrievals are utilized, (b) example of when only LEO retrievals are utilized, (c) final version of our daily AOD composite product.

Table 5. Location of GFS profiles used to estimate the uncertainty associated with US standard profiles in the 6SV code4.

\begin{tabular}{lcccr}
\hline & Location & $\theta_{0}\left(^{\circ}\right)$ & $\theta\left(^{\circ}\right)$ & $R_{\text {sfc }}(\%)$ \\
\hline Tropical & $10^{\circ} \mathrm{N}, 100^{\circ} \mathrm{E}$ & 21 & 42 & 10 \\
Midlatitude & $40^{\circ} \mathrm{N}, 130^{\circ} \mathrm{E}$ & 42 & 46 & 5 \\
Subarctic & $55^{\circ} \mathrm{N}, 110^{\circ} \mathrm{E}$ & 54 & 62 & 15 \\
\hline
\end{tabular}

clusion of the GEO sensors improves the spatial coverage of AOD from $67 \%$ for the LEO sensors to $81 \%$ for our merged AOD product. The GEO sensors lead to an improvement in the spatial coverage of AOD as their high temporal resolution allows for the identification of more cloud-free and sunglintfree regions where a valid AOD can be retrieved.

\section{Uncertainties}

\subsection{Atmospheric profiles}

To understand the uncertainty with using temperature, water vapor, and ozone information from US standard profiles in the AOD retrieval procedure, we conducted a sensitivity analysis where atmospheric profiles from $0.5^{\circ} \times 0.5^{\circ}$ Global Forecast System (GFS) data were input into the 6SV model. We extracted the GFS profiles from locations that represent tropical, midlatitude, and subarctic conditions during January and July 2014, and used different $\theta_{0}, \theta$, and $R_{\mathrm{sfc}}$ for each location to assess their impact on the uncertainty (Table 5). Figure 7a shows compares several of these GFS profiles against the US standard profile to show that vastly different atmospheric conditions are being input into the 6SV. For this sensitivity analysis, we first run the 6SV in atmospheric correction mode to retrieve $\rho_{\min }$ for each profile, which is then used to retrieve $\rho_{\text {toa }}$. Note we perform this analysis on MTSAT-2, since its spectral response function extends to slightly larger wavelengths compared to GOES-15 where water vapor absorption has a stronger impact. Overall, $\rho_{\text {toa }}$ is very similar between the US standard and GFS profiles in each region (Fig. 8b), which proves that the standard profile is causing only a minimal amount of uncertainty in the AOD retrieval procedure. The uncertainty is slightly higher over subarctic locations due mostly to the much drier conditions than that in the US standard profile, but errors are still less than $1 \%$ for an AOD of 3 . 

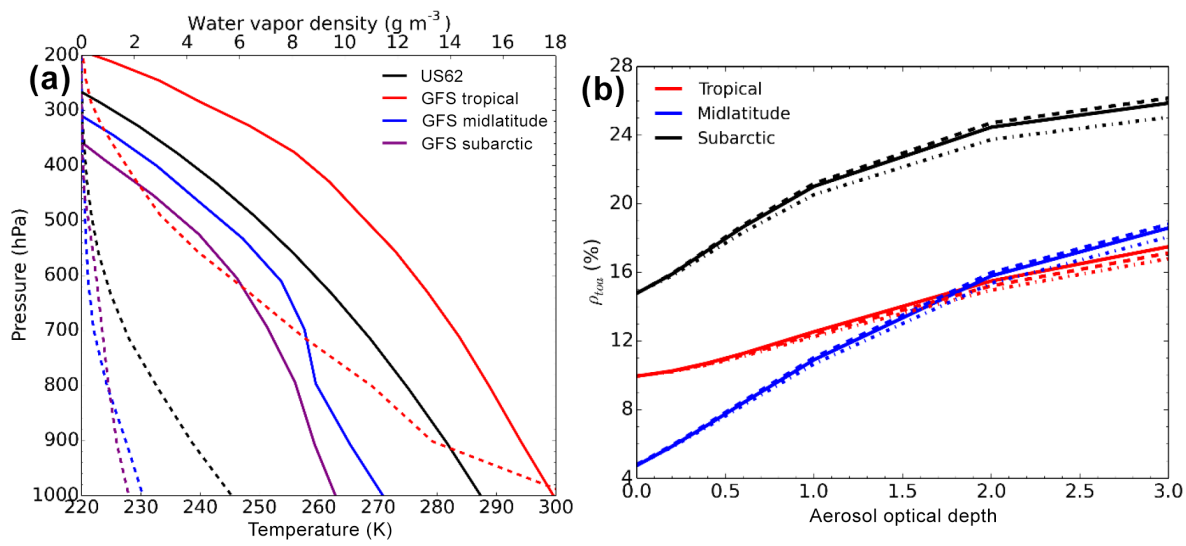

Figure 7. (a) Temperature (solid) and water vapor density (dashed) from the US standard profile and GFS profiles extracted from tropical, midlatitude, and subarctic regions. (b) 6SV model output of $\rho_{\text {toa }}$ for AOD ranging from 0 to 3 for US standard (solid) and GFS atmospheric profiles from January (dashed) and July (dotted/dashed) 2014 in different regions. Specified $\theta_{0}, \theta$, and $\mathrm{R}_{\text {sfc }}$ in Table 5 were additional inputs into the model.

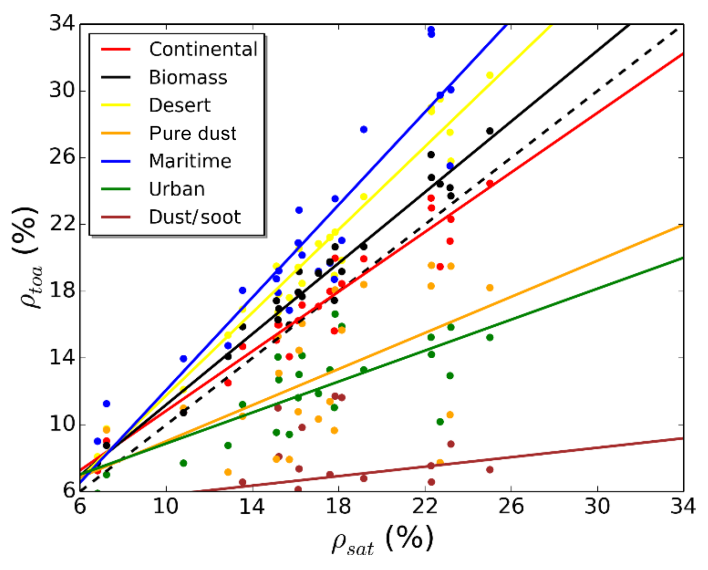

Figure 8. Observed $\rho_{\text {sat }}$ vs. $6 \mathrm{SV} \rho_{\text {toa }}$ results for 24 unique nondesert cases over eastern Asia during March and April 2014 where seven different aerosol models were tested for each case. Dust and pollution were the primary aerosol constituents during this period.

\subsection{Surface reflectance $\left(\boldsymbol{R}_{\mathrm{sfc}}\right)$ retrieval}

A significant source of uncertainty in our study is associated with the $R_{\text {sfc }}$ retrievals due to the variation in solar geometry throughout the 28 day period. Overall, we found that the uncertainty in AOD increases with decreasing $R_{\text {sfc }}$ values. For instance, the AOD uncertainty can be as high as $17 \%$ at $R_{\mathrm{sfc}}$ values of $10 \%$ but increase to almost $34 \%$ at $R_{\mathrm{sfc}}$ values of $5 \%$. Note that these values represent the maximum possible uncertainty that can be associated with a cloud-free $R_{\mathrm{sfc}}$ retrieval. Nevertheless, this uncertainty is the most likely explanation for the MTSAT/GOES AOD bias found over portions of the Pacific Ocean on 18 and 23 March. When attempting to use a 21- and 24-day period for the $R_{\text {sfc }}$ retrievals, we noticed major issues with cloud contamination that led to significant underestimations in AOD.

\subsection{Aerosol models}

The most significant assumption in creating the LUTs in our GEO AOD retrieval algorithms is the selection of the aerosol model as the simulated $\rho_{\text {toa }}$ can vary greatly based on the optical properties of the aerosols. In order to select the 6SV aerosol models that would introduce the least amount of uncertainty in our retrieval algorithms, we conducted a detailed comparison between the observed $\rho_{\text {sat }}$ and simulated $\rho_{\text {toa }}$ using seven different 6SV aerosol models for 24 unique cases occurring over AERONET stations across eastern Asia during March and April 2014. For each case, we provide the $6 \mathrm{SV}$ with the $R_{\mathrm{sfc}}$ retrieval value closest to the AERONET station along with precise values of $\theta_{0}, \theta$, and $\varphi$ from the MTSAT-2 imager, and AERONET $550 \mathrm{~nm}$ AOD. Then, we simulate the 6SV using these identical input values and compare the $\rho_{\text {toa }}$ values to the MTSAT- 2 imager $\rho_{\text {sat }}$ in order to determine the aerosol model with the least amount of uncertainty. Figure 8 presents the results from each aerosol model for the 24 cases where the continental model (red) simulated the most realistic $\rho_{\text {toa }}$ values, as $\rho_{\text {sat }}$ was slightly overestimated at values less than about $16 \%$ and underestimated at values greater than about $20 \%$. The average difference between $\rho_{\text {sat }}$ and $\rho_{\text {toa }}$ for the 24 cases was only $-0.1 \%$ when using the continental aerosol model leading to the lowest root mean square error (RMSE) of $1.3 \%$ (Table 6). SSA retrievals from the AERONET stations across eastern Asia were often around 0.90 at $500 \mathrm{~nm}$ with a decreasing trend at larger wavelengths, which is nearly identical to the prescribed SSA of the continental model. Although pollution events are observed frequently over eastern Asia, we were surprised by such excellent agreement between AERONET stations and the continental aerosol model due to the fact that dust emitted from the Taklamakan and Gobi deserts is often transported over eastern Asia, especially in the early spring, which is the fo- 
Table 6. Average difference between observed $\rho_{\text {sat }}$ and 6SV $\rho_{\text {toa }}$ for the 24 cases along with RMSE for each 6SV aerosol model. SSA at $500 \mathrm{~nm}$ is also shown for each aerosol model.

\begin{tabular}{lccc}
\hline 6SV aerosol & SSA & $\rho_{\text {sat }}(\%)-\rho_{\text {toa }}(\%)$ & RMSE $(\%)$ \\
\hline Desert & 0.95 & -3.45 & 3.84 \\
Urban & 0.69 & 4.86 & 5.79 \\
Continental & 0.9 & -0.09 & 1.31 \\
Maritime & 0.99 & -4.79 & 5.7 \\
Biomass & 0.94 & -1.63 & 1.9 \\
Pure dust & 0.72 & 4.19 & 5.84 \\
Dust/soot & 0.25 & 10.2 & 11.17 \\
\hline
\end{tabular}

cus of our study. This suggests that pure dust plumes, which are generally associated with SSA values of around 0.95 (Seinfeld et al., 2004; Hsu et al., 2006), often undergo modification to a polluted dust mixture with lower SSA values after being transported over the polluted region of eastern Asia. In fact, during the polluted dust case on 18 March 2014 (i.e., Fig. 2), SSA data from the Xianghe AERONET site were around 0.89 .

We found a couple of dust plumes nearby their source region in the Taklamakan desert on 25 and 29 April 2014. The Taklamakan AERONET site retrieved SSA values from 0.93 to 0.95 for these pure dust plumes, which are comparable to that found for dust during the Asian Pacific Regional Aerosol Characterization Experiment (ACE-Asia) from 30 March to 3 May 2001. Therefore, to better represent the dust optical properties, we also incorporated the desert aerosol model into our AOD retrieval algorithm, which uses a more appropriate SSA at $500 \mathrm{~nm}$ of about 0.95 that increases with larger wavelengths. Overall, for the instances when our AOD retrieval algorithm correctly identifies polluted and pure dust events, Table 6 suggests that RMSEs will be minimal $(\sim 1.3 \%)$. These errors can increase to about $3.8 \%$ for the instances when our algorithm incorrectly identifies pollution as dust or vice versa. We also observed smoke aerosols during the case studies presented in Sect. 4, which were shown to have SSA values as low as 0.85 during ACE-Asia (Seinfeld et al., 2004). Thus, we expect similar errors $(\sim 3.8 \%)$ for instances when our continental aerosol model is used to retrieve AOD in highly absorbing smoke plumes. Note that for scenes involving pure dust plumes, the RMSEs mentioned above are more representative of lower bound error estimates due to unrealistic dust scattering properties that can arise from the $6 \mathrm{SV}$ Mie-scattering calculations, which can lead to higher uncertainties in AOD (Dubovik et al., 2002; Levy et al., 2007b).

\subsection{NRT AOD composites}

When generating our AOD composite product, uncertainties may arise from averaging the individual GEO and LEO AOD retrievals onto a common grid (Sect. 3.6) due to differences in the AOD algorithms, spatial resolution, observation times, and viewing geometry. We expect minimal uncertainties when averaging the GEO AOD retrievals onto a common grid, since the GOES and MTSAT AOD algorithms and spatial resolutions are very similar. Additionally, there will only be a small number of instances when both GOES and MTSAT AOD retrievals fall within the same grid box due to the limited overlap between their geographical coverage. Conversely, when averaging the MODIS and VIIRS AOD, significant uncertainties may arise due to the differences between their AOD algorithms as discussed in Sect. 2.2. Figure 9ab shows an example of the MODIS Level 2 AOD retrievals and VIIRS AOD retrievals for the 18 March 2014 case study presented in Sect. 4.1. These LEO sensors show a very similar spatial distribution of AOD throughout the domain where both retrieve AOD $>1$ for the polluted dust plume extending northeast from eastern China $\left(\sim 33^{\circ} \mathrm{N}, 120^{\circ} \mathrm{E}\right)$ to the Sea of Japan $\left(\sim 36^{\circ} \mathrm{N}, 135^{\circ} \mathrm{E}\right)$ and AOD $>0.5$ throughout much of Southeast Asia $\left(\sim 16^{\circ} \mathrm{N}, 100^{\circ} \mathrm{E}\right)$. The most significant difference between the LEO AOD retrievals appears over the Korean peninsula $\left(\sim 38^{\circ} \mathrm{N}, 128^{\circ} \mathrm{E}\right)$, where MODIS and VIIRS AOD are around 0.7 and 0.5, respectively. Both algorithms utilize their dust models to retrieve AOD in this region; therefore, VIIRS is likely biased low due to the assumption of spherical dust particles in the model. Nevertheless, the correlation between VIIRS and MODIS AOD throughout this entire domain is very high $(R=0.92)$, which suggests that our approach of averaging VIIRS and MODIS AOD to generate the AOD composite leads to minimal uncertainties.

\section{Validation}

We validate our daily AOD composites using Level 1.5 AERONET $550 \mathrm{~nm}$ AOD from 15 different sites across East Asia and five different sites across the western United States during the 6-day period (18-23 March 2014) of the transPacific transport event presented in this paper. To conduct a proper validation, we calculated the average of all the available AERONET AOD retrievals for each site during the $24 \mathrm{~h}$ period of the daily AOD composites. Then, we use the nearest neighbor approach to find the closest composite grid box to each AERONET site. Figure 10a shows a high correlation $(R=0.87)$ between AERONET AOD and the daily AOD composites including only LEO satellite retrievals. The slope of the linear regression line indicates the high bias of about 0.10 in the LEO retrievals. Figure $10 \mathrm{~b}$ shows a slightly lower correlation of $R=0.79$ between AERONET AOD and our daily AOD composite product including both LEO and GEO satellite retrievals, which is not surprising considering the higher uncertainties associated with the GEO retrievals. However, the slope of the linear regression line has decreased to near 1.0 as our daily AOD composite product is associated with a high bias of only 0.024 . Overall, this validation exercise has shown that the improvement in AOD spatial coverage from the inclusion of the GEO retrievals in our AOD composite does not lead to a significantly degraded product. 


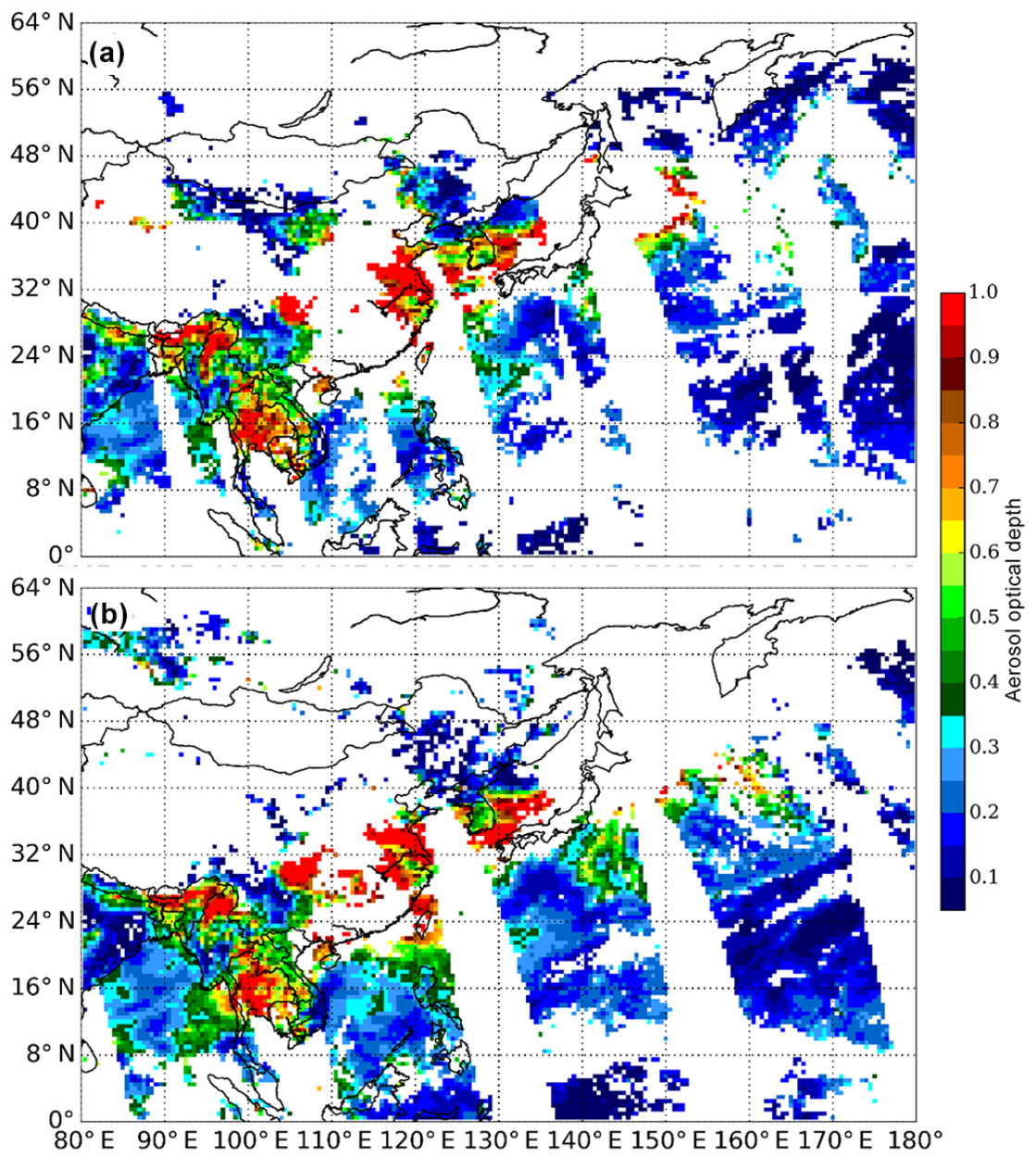

Figure 9. (a) MODIS Level 2 AOD retrievals and (b) VIIRS AOD retrievals for the 18 March 2014 case study presented in Sect. 4.1. The MODIS and VIIRS AOD retrievals are regridded onto identical domains for comparison purposes.
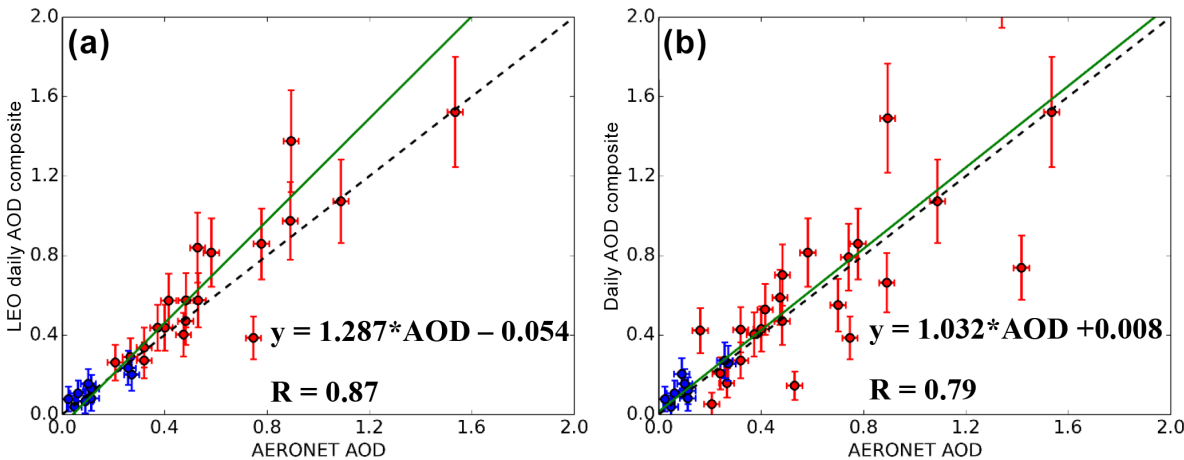

Figure 10. (a) Daily average of Level 1.5 AERONET $550 \mathrm{~nm}$ AOD retrievals vs. the daily AOD composite including only LEO satellite retrievals for the 6-day period from 18 to 23 March 2014 (Table 4). (b) Same as (a) except daily average of AERONET AOD retrievals vs. our daily AOD composite product (GEO and LEO retrievals). AERONET AOD data from 15 different sites across East Asia (red) and five different sites across the western United States (blue) were used to validate the daily AOD composites. Error bars are based on \pm 0.015 uncertainty for AERONET AOD retrievals, $\pm 0.05 \pm 0.15 \times$ AOD for LEO retrievals, and $25 \%$ uncertainty for our daily AOD composite product. The $25 \%$ uncertainty is the average of the GEO uncertainty range (18-34\%). The linear regression lines are in solid green, with corresponding equations and correlation coefficients in the lower right corner. 
Thus, our composite product can be used with confidence for quantitatively tracking aerosol plumes.

\section{Conclusion}

The primary goal of this study was to generate a NRT daily AOD composite product that combines GEO and LEO satellite observations to assist with monitoring and tracking the trans-Pacific transport of aerosol plumes. In this paper, we present examples of the AOD composite product for a case study of trans-Pacific transport of Asian aerosols in midMarch 2014. Although the MODIS and VIIRS LEO satellites generally provide high-quality AOD retrievals in cloud-free scenes (excluding the polar region), they only observe the same area once during the daytime period, which increases the likelihood of cloud and sun glint contamination. This can cause gaps in daily AOD coverage as shown by the case studies presented in this paper. Thus, we take advantage of the high temporal resolution of the GOES-15 and MTSAT2 GEO satellites by developing AOD retrieval algorithms based on the continental and desert aerosol models in the 6SV1.1 RTM. We also develop a unique cloud/dust detection algorithm utilizing spectral, spatial, and temporal techniques to disregard cloud-contaminated pixels and locate dust pixels for the desert aerosol model. Overall, when merging the GEO and LEO retrievals, we generated a daily AOD composite product that provided additional spatial coverage of AOD across our domain from Asia to North America. We showed that the coverage of aerosol plumes propagating from Asia to the western Pacific were better captured by our AOD composite product than the individual GEO and LEO products. Our AOD composite also showed increased spatial coverage of AOD across the eastern Pacific, which can assist with tracking the trans-Pacific transport of aerosols. Additionally, the incorporation of the $6 \mathrm{SV}$ desert model into our AOD retrieval algorithms helped depict areas of dust plumes over the Gobi and Taklamakan deserts that were not shown by the LEO products.

Although the AOD composite product showed an increase in spatial coverage of AOD across our domain from Asia to North America, we noted several issues pertaining to the GEO AOD retrievals. We showed that high biases in AOD can appear in the tropical Pacific due to cloud artifacts impacting the GEO retrievals, which were more apparent over the tropical western Pacific than over the tropical eastern Pacific. Additionally, we found low biases in AOD that were associated with cloud artifacts impacting the 28-day composite technique and $R_{\text {sfc }}$ retrieval procedure. The variation in solar geometry during the 28-day composite technique can also lead to uncertainties in AOD of up to $34 \%$ over areas of minimal $R_{\text {sfc }}$ such as the tropical Pacific. We did not discuss uncertainties in the GOES AOD retrieval algorithm over land as we are mostly concerned with tracking the aerosol plumes during their transport to the west coast of North America. Nevertheless, our assessment of the GOES AOD retrieval al- gorithm over land showed that it performs adequately over the west coast of the United States.

We did not show examples of the 6-hourly AOD composite product, since the daily product is more pertinent for the focus of this paper where we track the trans-Pacific transport of aerosols. Nevertheless, it is important to note that the GEO AOD retrievals have a greater impact on this product, since LEO satellites have limited coverage across our domain during the $6 \mathrm{~h}$ time window. Thus, the 6-hourly product can have important implications for aerosol forecasting, as the shorter time window is more appropriate for the AOD assimilation process. Thus, the assimilation of both LEO and GEO satellite AOD retrievals can provide a more comprehensive coverage of AOD into chemistry models (e.g., Weather Research and Forecasting coupled with Chemistry (WRF-Chem)), which can help improve the representation of the simulated aerosol fields. This can ultimately improve air quality forecasts and the simulation of the aerosol-cloudprecipitation processes.

The future capability of GEO satellites for monitoring and tracking aerosol plumes will be greatly enhanced with the upcoming launch of the next-generation NOAA GOES-R and recently launched JMA Himawari-8 satellites. These advanced GEO satellites perform full disk scans every $5 \mathrm{~min}$, and carry sensors consisting of 16 spectral bands with $0.5 \mathrm{~km}$ spatial resolution at nadir for the $0.64 \mu \mathrm{m}$ visible band with a spectral resolution from about 0.59 to $0.69 \mu \mathrm{m}$. Uncertainties associated with GEO AOD retrievals will be greatly reduced when using GOES-R and Himawari-8 measurements. In addition, the much improved spatial resolution of these satellites will help track aerosol plumes across the northern Pacific. This paper showed that GOES-15 and MTSAT-2 do not have adequate spatial resolution to track aerosol plumes in the northern parts of the Pacific. The very high temporal resolution of $5 \mathrm{~min}$ for the new-generation satellites will also lead to a more complete understanding of the aerosol spatial distribution across the Pacific.

\section{Data availability}

Aqua and Terra MODIS AOD products are available in near-real time at https://lance.modaps.eosdis.nasa.gov/ data_products/ (NASA, 2015). The VIIRS AOD product is available at http://www.class.ncdc.noaa.gov/saa/products/ catSearch (NOAA, 2015). AERONET AOD data are accessible at http://aeronet.gsfc.nasa.gov/ (NASA, 2016). MISR AOD and CALIPSO data products are both accessible via the Atmospheric Science Data Center at NASA Langley Research Center: https://eosweb.larc.nasa.gov/ (ASDC, 2015). The online HYSPLIT tool from NOAA Air Resources is available at http://ready.arl.noaa.gov/HYSPLIT.php (ARL, 2016). 
Acknowledgements. We acknowledge the Land, Atmosphere Near real-time Capability for Earth observing system (LANCE) for access to the MODIS Level 2 AOD products. LANCE is operated by the NASA/GSFC/Earth Science Data and Information System (ESDIS) with funding provided by NASA/HQ. We also thank the NOAA Comprehensive Large Array-data Stewardship System (CLASS) subscription service for near-real-time delivery of AOD data from the VIIRS Environmental Data Record, the Atmospheric Science Data Center at NASA Langley Research Center for access to the MISR and CALIOP data products, and the NOAA Air Resources Laboratory (ARL) for the provision of the HYSPLIT transport and dispersion model and READY website (http://www.ready.noaa.gov). We thank the site managers on the AERONET team for establishing and maintaining their sites, and the anonymous reviewers who helped improve this paper through their useful comments.

Edited by: F. Boersma

\section{References}

Ackerman, S., Strabala, K., Menzel, P., Frey, R., Moeller, C., Gumley, L., Baum, B., Seemann, S. W., and Zhang, H.: Discriminating clear-sky from cloud with MODIS: Algorithm theoretical basis document (MOD35), version 5.0, NASA Goddard Space Flight Cent., Greenbelt, MD, USA, 2006.

Ackerman, S. A.: Remote sensing aerosols using satellite infrared observations, J. Geophys. Res., 102, 17069-17079, 1997.

Ackerman, S. A., Holz, R. E., Frey, R., Eloranta, E. W., Maddux, B. C., and McGill, M.: Cloud detection with MODIS. Part II: validation, J. Atmos. Ocean. Tech., 25, 1073-1086, 2008.

Al-Saadi, J., Szykman, J., Pierce, B. R., Kittaka, C., Neil, D., Chu, D. A., Remer, L., Gumley, L., Prins, E., Weinstock, L., MacDonald, C., Wayland, R., Dimmick, F., and Fishman, J.: Improving national air quality forecasts with satellite aerosol observations, B. Am. Meteorol. Soc., 86, 1249-1261, doi:10.1175/BAMS-869-1249, 2005.

ARL: HYSPLIT Trajectory Model, available at: http://ready.arl. noaa.gov/HYSPLIT.php, last access: March 2016.

ASDC: Level 1B CALIOP Lidar Calibrated and Geo-located Profiles Version 3.30 (CAL_LID_L1-ValStage1-V3-30), available at: https://eosweb.larc.nasa.gov/, last access: September 2015.

Ault, A. P., Williams, C. R., White, A. B., Neiman, P. J., Creamean, J. M., Gaston, C. J., Ralph, F. M., and Prather, K. A.: Detection of Asian dust in California orographic precipitation, J. Geophys. Res., 116, D16205, doi:10.1029/2010JD015351, 2011.

Benjamin, S. G., Weygandt, S. S., Brown, J. M., Hu, M., Alexander, C., Smirnova, T. G., Olson, J. B., James, E., Dowell, D. C., Grell, G. A., Lin, H., Peckham, S. E., Smith, T. L., Moninger, W. R., Kenyon J., and Manikin, G. S.: A North American Hourly Assimilation and Model Forecast Cycle: The Rapid Refresh, Mon. Weather Rev., 144, 1669-1694, doi:10.1175/MWR-D-150242.1, 2016.

Diner, D. J., Beckert, J. C., Bothwell, G. W., and Rodrigues, J. I.: Performance of the MISR instrument during its first 20 months in Earth orbit, IEEE T. Geosci. Remote, 40, 1449-1466, 2002.

Dubovik, O., Smirnov, A., Holben, B. N., King, M. D., Kaufman, Y. J., Eck, T. F., and Slutsker, I.: Accuracy assessments of aerosol optical properties retrieved from Aerosol Robotic Network (AERONET) Sun and sky radiance measurements, J. Geophys. Res., 105, 9791-9806, 2000.

Dubovik, O., Holben, B. N., Lapyonok, T., Sinyuk, A., Mishchenko, M. I., Yang, P., and Slutsker, I.: Non-spherical aerosol retrieval method employing light scattering by spheroids, Geophys. Res. Lett., 29, 54-1-54-4, doi:10.1029/2001GL014506, 2002.

Dubovik, O., Sinyuk, A., Lapyonok, T., Holben, B. N., Mishchenko, M., Yang, P., Eck, T. F., Volten, H., Munoz, O., Weihelmann, B., van der Zande, W. J., Leon, J.-F., Sokorin, M., and Slutsker, I.: Application of spheroid models to account for aerosol particle nonspericity in remote sensing of desert dust, J. Geophys. Res., 11, D11208, doi:10.1029/2005JD006619, 2006.

Eck, T. F., Holben, B. N., Reid, J. S., Dubovik, O., Smirnov, A., O’Neill, N. T., Slutsker, I., and Kinne, S.: Wavelength dependence of the optical depth of biomass burning, urban, and desert dust aerosols, J. Geophys. Res.-Atmos., 104, 31333 31349, 1999.

Frey, R. A., Ackerman, S. A., Liu, Y. H., Strabala, K. I., Zhang, H., Key, J. R., and Wang, X. G.: Cloud detection with MODIS. Part I: improvements in the MODIS cloud mask for collection 5, J. Atmos. Ocean. Tech., 25, 1057-1072, 2008.

Gong, S. L., Zhang, X. Y., Zhao, T. L., Zhang, X. B., Barrie, L. A., McKendry, I. G., and Zhao, C. S.: A simulated climatology of Asian dust aerosol and its trans-Pacific transport. Part II: Interannual variability and climate connections, J. Climate, 19, 104122, 2006.

Hillger, D., Kopp, T., Lee, T., Lindsey, D., Seaman, S., Miller, S., Solbrig, J., Kidder, S., Bachmeier, S., Jasmin, T., and Rink, T.: First-Light Imagery from Suomi NPP VIIRS, B. Am. Meteorol. Soc., 94, 1019-1029, 2013.

Holben, B. N., Eck, T. F., Slutsker, I., Tanŕe, D., Buis, J. P., Setzer, A., Vermote, E., Reagan, J. A., Kaufman, Y. J., Nakajima, T., Lavenu, F., Jankowiak, I., and Smirnov, A.: AERONET - A federated instrument network and data archive for aerosol characterization, Remote Sens. Environ., 66, 1-16, 1998.

Hsu, N. C., Tsay, S.-C., King, M. D., and Herman, J. R.: Deep blue retrievals of Asian aerosol properties during ACE-Asia, IEEE T. Geosci. Remote, 44, 3180-3195, 2006.

Huang, J., Hsu, N. C., Tsay, S.-C., Jeong, M.-J., Holben, B. N., Berkoff, T. A., and Welton, E. J.: Susceptibility of aerosol optical thickness retrievals to thin cirrus contamination during the BASE-ASIA campaign, J. Geophys. Res., 116, D08214, doi:10.1029/2010JD014910, 2011.

Ignatov, A. and Stowe, L.: Aerosol Retrievals from Individual AVHRR Channels. Part I: Retrieval Algorithm and Transition from Dave to 6S Radiative Transfer Model, J. Atmos. Sci., 59, 313-334, 2002.

Jackson, J., Liu, H., Laszlo, I., Kondragunta, S., Remer, L. A., Huang, J., and Huang, H.-C.: Suomi-NPP VIIRS Aerosol Algorithms and Data Products, J. Geophys. Res., 118, 12673-12689, doi:10.1002/2013JD020449, 2013.

Jethva, H., Torres, O., Remer, L. A., and Bhartia, P. K.: A Color Ratio Method for Simultaneous Retrieval of Aerosol and Cloud Optical Thickness of Above-Cloud Absorbing Aerosols From Passive Sensors: Application to MODIS Measurements, IEEE T. Geosci. Remote, 51, 3862-3870, doi:10.1109/TGRS.2012.2230008, 2013. 
Kahn, R. A., Gaitley, B. J., Martonchik, J. V., Diner, D. J., Crean, K. A., and Holben, B.: Multiangle Imaging Spectroradiometer (MISR) global aerosol optical depth validation based on 2 years of coincident Aerosol Robotic Network (AERONET) observations, J. Geophys. Res., 110, D10S04, doi:10.1029/2004JD004706, 2005.

Khain, A., Rosenfeld, D., and Pokrovsky, A., Aerosol impact on the dynamics and microphysics of deep convective clouds, Q. J. Roy. Meteor. Soc., 131, 2639-2663, 2005.

Kim, J., Yoon, J. M., Ahn, M. H., Sohn, B. J., and Lim, H. S.: Retrieving aerosol optical depth using visible and mid-IR channels from geostationary satellite, MTSAT-1R, Int. J. Remote Sens., 29, 6181-6192, 2008.

Knapp, K. R., Frouin, R., Kondragunta, S., and Prados, A. I.: Towards aerosol optical Depth retrievals over land from GOES visible radiances: Determining surface reflectance, Int. J. Remote Sens., 26, 4097-4116, 2005.

Kotchenova, S. Y. and Vermote, E. F.: Validation of a vector version of the $6 \mathrm{~S}$ radiative transfer code for atmospheric correction of satellite data. Part II: Homogeneous Lambertian and anisotropic surfaces, Appl. Optics, 46, 4455-4464, 2007.

Kotchenova, S. Y., Vermote, E. F., Matarrese, R., and Klemm Jr., F.: Validation of a vector version of the $6 \mathrm{~S}$ radiative transfer code for atmospheric correction of satellite data. Part I: Path radiance, Appl. Optics, 45, 6762-6774, 2006.

Levy, R. C., Remer, L. A., Mattoo, S., Vermote, E. F., and Kaufman, Y. J.: Second-generation operational algorithm: Retrieval of aerosol properties over land from inversion of Moderate Resolution Imaging Spectroradiometer spectral reflectance, J. Geophys. Res., 112, D13211, doi:10.1029/2006JD007811, 2007a.

Levy, R. C., Remer, L. A., and Dubovik, O.: Global aerosol optical properties and application to Moderate Resolution Imaging Spectroradiometer aerosol retrieval over land, J. Geophys. Res., 112, D13210, doi:10.1029/2006JD007815, 2007b.

Levy, R. C., Remer, L. A., Kleidman, R. G., Mattoo, S., Ichoku, C., Kahn, R., and Eck, T. F.: Global evaluation of the Collection 5 MODIS dark-target aerosol products over land, Atmos. Chem. Phys., 10, 10399-10420, doi:10.5194/acp-10-10399-2010, 2010.

Levy, R. C., Mattoo, S., Munchak, L. A., Remer, L. A., Sayer, A. M., Patadia, F., and Hsu, N. C.: The Collection 6 MODIS aerosol products over land and ocean, Atmos. Meas. Tech., 6, 29893034, doi:10.5194/amt-6-2989-2013, 2013.

Liu, H., Remer, L. A., Huang, J., Huang, H.-C., Kondragunta, S., Laszlo, I., Oo, M., and Jackson, J. M.: Preliminary evaluation of S-NPP VIIRS aerosol optical thickness, J. Geophys. Res., 119, 3942-3962, 2014.

Mace, G. G., Zhang, Q., Vaughan, M., Marchand, R., Stephens, G., Trepte, C., and Winker, D.: A description of hydrometer layer occurrence statistics derived from the first year of merged Cloudsat and CALIPSO data, J. Geophys. Res., 114, D00A26, doi:10.1029/2007JD009755, 2009.

Mecikalski, J. R., MacKenzie Jr., W. M., König, M., and Muller, S.: Cloud-Top Properties of Growing Cumulus prior to Convective Initiation as Measured by Meteosat Second Generation. Part II: Use of Visible Reflectance, J. Appl. Meteorol. Clim., 49, 2544 2558, 2010.

Meyer, K., Platnick, S., and Zhang, Z.: Simultaneously inferring above-cloud absorbing aerosol optical thickness and underlying liquid phase cloud optical and microphysical prop- erties using MODIS, J. Geophys. Res., 120, 5524-5547. doi:10.1002/2015JD023128, 2015.

Molod, A., Takacs, L., Suarez, M., Bacmeister, J., Song, I.-S., and Eichmann, A.: The GEOS-5 atmospheric general circulation model: Mean climate and development from MERRA to Fortuna, NASA Tech. Rep. NASA TM-2012-104606, 28, 117 pp., 2012.

Naeger, A. R., Christopher, S. A., and Johnson, B. T.: Multiplatform analysis of the radiative effects and heating rates for an intense dust storm on 21 June 2007, J. Geophys. Res., 118, 9316-9329, 2013a.

Naeger, A. R., Christopher, S. A., Ferrare, R., and Liu, Z.: A new technique using infrared satellite measurements to improve the accuracy of the CALIPSO cloud-aerosol discrimination method, IEEE T. Geosci. Remote, 51, 642-653, 2013 b.

NASA: Level 2 Aerosol, 5-Min Swath $10 \mathrm{~km}$ data set (Terra MOD04_L2, Aqua - MYD04_L2), available at: https://lance. modaps.eosdis.nasa.gov/data_products/, last access: September 2015.

NASA: Level 1.5 cloud-screened aerosol optical depth (AOD), available at: http://aeronet.gsfc.nasa.gov/, last access: March 2016.

NOAA: VIIRS Environmental Data Record (VIIRS_EDR), available at: http://www.class.ncdc.noaa.gov/saa/products/catSearch, last access: September 2015.

Paciorek, C. J., Liu, Y., Macias, H. M., and Kondragunta, S.: Spatiotemporal associations between GOES aerosol optical depth retrievals and ground-level $\mathrm{PM}_{2.5}$, Environ. Sci. Technol., 42, 5800-5806, 2008.

Pope, C. A., Burnett, R. T., Thun, M. J., Calle, E. E., Krewski, D., Ito, K., and Thurston, G. D.: Lung cancer, cardiopulmonary mortality, and long-term exposure to fine particulate air pollution, JAMA-J. Am. Med. Assoc., 287, 1132-1141, 2002.

Prados, A. I., Kondragunta, S., Ciren, P., and Knapp, K. R., GOES Aerosol/Smoke Product (GASP) over North America: Comparisons to AERONET and MODIS observations, J. Geophys. Res., 112, D15201, doi:10.1029/2006JD007968, 2007.

Remer, L. A., Kaufman, Y. J., Tanré, D., Mattoo, S., Chu, D. A., Martins, J. V., Li, R.-R., Ichoku, C., Levy, R. C., Kleidman, R. G., Eck, T. F., Vermote, E., and Holben, B. N.: The MODIS Aerosol Algorithm, Products, and Validation, J. Atmos. Sci., 62, 947-973, doi:10.1175/JAS3385.1, 2005.

Remer, L. A., Mattoo, S., Levy, R. C., and Munchak, L. A.: MODIS $3 \mathrm{~km}$ aerosol product: algorithm and global perspective, Atmos. Meas. Tech., 6, 1829-1844, doi:10.5194/amt-6-1829-2013, 2013.

Rienecker, M. M., Suarez, M. J., Todling, R., Bacmeister, J., Takacs, L., Liu, H.-C., Gu, W., Sienkiewicz, M., Koster, R. D., Gelaro, R., Stajner, I., and Nielsen, J. E.: The GEOS-5 data assimilation system - documentation of versions 5.0.1 and 5.1.0, and 5.2.0, NASA Tech. Rep. NASA/TM-2008-104606, 27, 92 pp., 2008.

Rolph, G. D.: Real-time Environmental Applications and Display sYstem (READY) Website (http://www.ready.noaa.gov), NOAA Air Resources Laboratory, College Park, MD, USA, 2016.

Schmid, B., Michalsky, J., Halthore, R.,Beauharnois, M., Harrison, L., Livingston, J., Russell, P., Holben, B., Eck, T., and Smirnov, A.: Comparison of aerosol optical depth from four solar radiometers during the fall 1997 ARM intensive observation period, Geophys. Res. Lett., 26, 2725-2728, 1999. 
Seinfeld, J. H., Carmichael, G. R., Arimoto, R., Conant, W. C., Brechtel, F. J., Bates, T. S., Cahill, T. A., Clarke, A. D., Doherty, S. J., Flatau, P. J., Huebert, B. J., Kim, J., Markowicz, K. M., Quinn, P. K., Russell, L. M., Russell, P. B., Shimizu, A., Shinozuka, Y., Song, C. H., Tang, Y. H., Uno, I., Vogelmann, A. M., Weber, R. J., Woo, J. H., and Zhang, X. Y.: ACE-ASIA - Regional climatic and atmospheric chemical effects of Asian dust and pollution, B. Am. Meteorol. Soc., 85, 367-380, 2004.

Sokolik, I. N.: The spectral radiative signature of windblown mineral dust: Implications for remote sensing in the thermal IR region, Geophys. Res. Lett., 29, 2154, doi:10.1029/2002GL015910, 2002.

Streets, D. G., Yarber, K. F., Woo, J.-H., and Carmichael, G. R.: Biomass burning in Asia: Annual and seasonal estimates and atmospheric emissions, Global Biogeochem. Cy., 17, 1099, doi:10.1029/2003GB002040, 2003.

Talbot, R. W., Dibb, J. E., Lefer, B. L., Bradshaw, J. D., Sandholm, S. T., Blake, D. R., Blake, N. J., Sachse, G. W., Collins Jr., J. E., Heikes, B. G., Merrill, J. T., Gregory, G. L., Anderson, B. E., Singh, H. B., Thornton, D. C., Bandy, A. R., and Pueschel, R. F.: Chemical characteristics of continental outflow from Asia to the troposphere over the western Pacific Ocean during FebruaryMarch 1994: Results from PEM-West B, J. Geophys. Res., 102, 28255-28274, doi:10.1029/96JD02340, 1997.

Torres, O., Jethva, H., and Bhartia, P. K.: Retrieval of Aerosol Optical Depth above Clouds from OMI Observations: Sensitivity Analysis and Case Studies, J. Atmos. Sci., 69, 1037-1053, doi:10.1175/JAS-D-11-0130.1, 2012.

Vermote, E. F. and Kotchenova, S.: Atmospheric correction for the monitoring of land surfaces, J. Geophys. Res., 113, D23S90, doi:10.1029/2007JD009662, 2008.
Wen, G., Cahalan, R. F., Tsay, S.-C., and Oreopoulos, L.: Impact of cumulus cloud spacing on Landsat atmospheric correction and aerosol retrieval, J. Geophys. Res., 106, 12129-12138, doi:10.1029/2001JD900159, 2001.

Wilkening, K. E., Barrie, L. A., and Engle, M.: Transpacific air pollution, Science, 290, 65-67, 2000.

Winker, D. M., Pelon, J. R., and McCormick, M. P.: The CALIPSO mission: Spaceborne lidar for observation of aerosols and clouds, in Proc. SPIE, 4893, 1-11, 2003.

Winker, D. M., Pelon, J., Coakley Jr., J. A., Ackerman, S. A., Charlson, R. J., Colarco, P. R., Flamant, P., Fu, Q., Hoff, R. M., Kittaka, C., Kubar, T. L., Le Treut, H., McCormick, M. P., Mégie, G., Poole, L., Powell, K., Trepte, C., Vaughan, M. A., and Wielicki, B. A.: The CALIPSO Mission: A Global 3D View of Aerosols and Clouds, B. Am. Meteorol. Soc., 91, 1211-1229, 2010.

Witek, M. L., Garay, M. J., Diner, D. J., and Smirnov, A.: Aerosol optical depths over oceans: A view from MISR retrievals and collocated MAN and AERONET in situ observations, J. Geophys. Res., 118, 12620-12633, 2013.

Yu, H., Remer, L. A., Chin, M., Bian, H., Tan, Q., Yuan, T., and Zhang, Y.: Aerosols from overseas rival domestic emissions over North America, Science, 337, 566-569, 2012.

Zhang, J., Reid, J. S., and Holben, B. N.: An analysis of potential cloud artifacts in MODIS over ocean aerosol optical thickness products, Geophys. Res. Lett., 32, L15803, doi:10.1029/2005GL023254, 2005.

Zhao, T. L., Gong, S. L., Zhang, X. Y., Blanchet, J. P., McKendry, I. G., and Zhou, Z. J.: A simulated climatology of Asian dust aerosol and its trans-Pacific transport. Part I: Mean climate and validation, J. Climate, 19, 88-103, 2006. 